
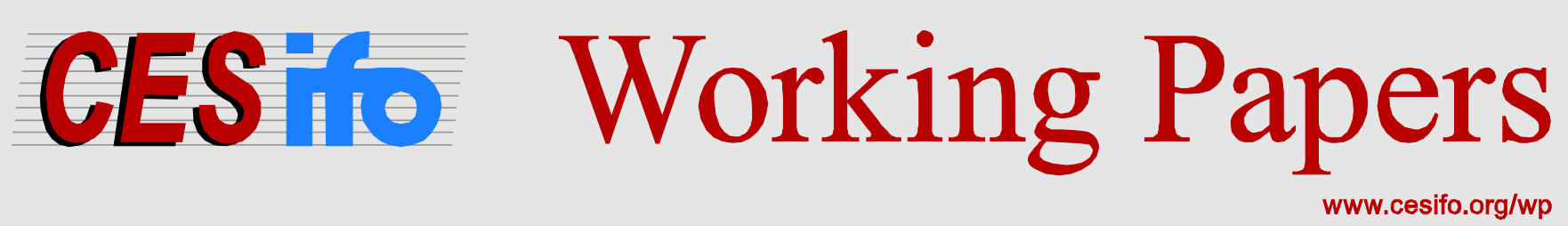

\title{
The Limits of Political Compromise: Debt Ceilings and Political Turnover
}

\author{
Alexandre B. Cunha \\ Emanuel Ornelas
}

\author{
CESIFO WORKING PAPER NO. 6429 \\ CATEgORY 6: Fiscal POLICY, MACROECONOMICS AND GROWTH \\ MARCH 2017
}

An electronic version of the paper may be downloaded

- from the SSRN website:

- from the RePEc website:

- from the CESifo website:

www.SSRN.com

www.RePEc.org

www.CESifo-group.org/wp 


\title{
The Limits of Political Compromise: Debt Ceilings and Political Turnover
}

\begin{abstract}
We study the desirability of limits on the public debt and of political turnover in an economy where incumbents have an incentive to set public expenditures above the socially optimal level due to rent-seeking motives. Parties alternate in office and cannot commit to future policies, but they can forge a political compromise where each party curbs excessive spending when in office if it expects future governments to do the same. In contrast to the received literature, we find that strict limits on government borrowing can exacerbate political economy distortions by making a political compromise unsustainable. This tends to happen when political turnover is limited. Conversely, a tight limit on the public debt fosters a compromise that yields the efficient outcome if political turnover is vigorous. Our analysis thus suggests that to sustain good economic policies, a society needs to restrict either the extent of political turnover or the ability of governments to issue debt, but not both.
\end{abstract}

JEL-Codes: E610, E620, H300, H630.

Keywords: debt limits, political turnover, efficient policies, fiscal rules.

\author{
Alexandre B. Cunha \\ Federal University of Rio de Janeiro \\ Rio de Janeiro / Brazil \\ research@alexbcunha.com
}

\author{
Emanuel Ornelas* \\ Sao Paulo School of Economics-FGV \\ Brazil - 01332-000 Sao Paulo \\ eaornelas@gmail.com
}

*corresponding author

March 24, 2017

This is a substantially revised version of CESifo Working Paper No. 4737, including the title. This will be the final version of the paper, as accepted for publication at the Journal of the European Economic Association.

We thank Dirk Krueger (the editor) and two anonymous referees for very useful comments and suggestions on a previous version of the paper. We also thank Paulo Arvate, Braz Camargo, Tiago Cavalcanti, Allan Drazen, Claudio Ferraz, Jon Fiva, Bernardo Guimaraes, Delfim G. Neto, Mattias Polborn, B. Ravikumar, Nico Voigtländer, Rodrigo Wagner and participants at several seminars for helpful comments. And we thank Carlos Eduardo Ladeira for competent research assistance. Cunha and Ornelas acknowledge financial support from the Brazilian Council of Science and Technology (CNPq). Ornelas also acknowledges financial support from the LSE Santander Travel Fund. 


\section{Introduction}

Whenever the public debt starts to rise quickly, as it has in most developed economies since 2008, a debate on the merits of debt limits resurfaces. The debate has been heightened by successive American "debt-ceiling crises" triggered by Congress' reluctance to relax the federal debt ceiling. In this paper we show that the desirability of limits on the public debt hinges on the degree of political turnover prevailing in the economy. If political turnover is high, a tight debt ceiling facilitates the implementation of efficient policies, but not otherwise. In particular, in a bipartisan society where each party tends to hold office every other term, but where political economy frictions are severe, the efficient policy is most likely to be sustainable if government access to the public debt is left unrestricted. Thus, in contrast to the general view that fiscal rules can only mitigate political economy distortions (albeit at the cost of reducing flexibility), we show that a debt ceiling aggravates them only if a small number of political parties rotate in office.

At a more general level, we uncover a tradeoff for the sustainability of socially desirable economic policies. If the laws regulating the formation of political parties are loose, constraints on government borrowing must be tight. But if the restrictions on formal political participation are stringent, then the government should be left free to borrow.

Our results also underscore a subtle impact of political turnover on economic performance. Political turnover matters for economic outcomes because it allows voters to discipline bad governments and to find alternatives to unskilled/selfish incumbents. We shut out both the disciplining and the selection effects of elections: we model political parties as rent-seeking but identical and unable to commit to future economic policies. Despite abstracting from those issues, we still find that the degree of political turnover is critical to determine the political feasibility of socially beneficial policies. ${ }^{1}$

The key mechanism rests on the possibility of intertemporal cooperation among political parties (a "political compromise") aimed at neutralizing the policy inefficiencies that stem from political frictions. The parties have an incentive to cooperate because policies affect their payoffs when they are out of office, when they do not enjoy the perks and rents created by the policies but bear the consequences of the inefficiencies they introduce in the economy. A political compromise puts a brake on the current gains of the incumbent but can improve its future payoff. Whether it is sustainable depends on both the degree

\footnotetext{
${ }^{1}$ In the literature, the terms political turnover, political instability, political competition, political fragmentation and power persistence are often used interchangeably to denote phenomena related to situations when the identity of those who hold power changes over time. We stick with 'political turnover' for most of the text, but occasionally also use the near-synonyms mentioned above.
} 
of political competition and the constraints on government borrowing.

We embed the analysis in a simple, standard, neoclassic economic structure. In each period, households decide how much to work and consume, while competitive firms decide how much to produce under a constant returns to scale technology that uses labor as input. The government provides a public good that is financed through either taxes or debt. The government can borrow from the international markets at a fixed interest rate - we rule out the possibility of default. The political structure is possibly the simplest that allows us to study our main question. There is an exogenous number of competing parties, which are unable to commit to policies. The political friction stems from incumbents and opposition parties having different preferences. Specifically, the period payoff of opposition parties is proportional to the representative household period utility, whereas incumbents enjoy some extra gain from government consumption. This results in incumbents having quasihyperbolic preferences, as defined by Laibson (1997), with the implication that the party in power has an incentive to spend more than is socially optimal. ${ }^{2}$ Political turnover is determined by a random process in which the probability that a given party holds power in each period is inversely related to the number of active political parties.

A tighter debt ceiling lowers the incumbent's short-run gain from not cooperating, since it limits how much it can extract from future resources. The size of this reduction is independent of the degree of political turnover. Under a political compromise aimed at implementing the efficient policy (which maximizes society's welfare), the rent benefit for future governments falls under a tight constraint on government borrowing, but rises when access to the debt is loose. Critically, this difference is more important when turnover is lower (because this is when future rents matter more). It follows that when electoral rules are such that few parties participate in the political process, tight constraints on the public debt tend to undermine the feasibility of a political compromise. If instead numerous political parties actively compete, strong limits on government borrowing tend to foster a compromise. The upshot is that the desirability of tight fiscal rules is inversely related to the stringency of the rules allowing formal political participation.

We build the intuition for the general case by developing the polar cases of no debt and unconstrained debt, which we then extend to encompass all intermediary levels of debt limits. When debt is unavailable, we find that the efficient policy is unachievable if

\footnotetext{
${ }^{2}$ Such preferences imply that, in period $t$, the marginal rate of substitution between $t$ and $t+1$ is lower than the marginal rate of substitution between $t+s$ and $t+s+1, s \geq 1$. Government preferences with this property are common in recent political economy models (e.g., Aguiar and Amador 2011, Halac and Yared 2014).
} 
politicians are too profligate, since in that case the short-run temptation to spend is too large. Otherwise, a political compromise where all parties implement the efficient policy when in power can be sustained provided there is enough political turnover. The intuition is simple. With strong turnover, the probability that the incumbent will return to power and enjoy office rents in the future is low, while the probability that it will suffer the economic consequences of government rent-seeking when out of power is high. Hence it pays to forge a compromise that limits rents (and improves the economy's performance) when many political parties compete for office. This is not advantageous, however, when each party expects to hold office frequently.

Now, if the government were free to issue public debt, and thus to shape the action space of future administrations, the intuitive result just described is largely overturned. We concentrate on the more interesting case where politicians' prodigality is high enough so that there is an equilibrium in which the first incumbent increases government expenditures so much that the public debt reaches its maximum sustainable level. That would drive the country into immiseration: a permanent state of low consumption and high debt. Under the shadow of that bad equilibrium, we find that the efficient policy can be sustained as an equilibrium outcome only when political competition is not too intense. The intuition is as follows. Without cooperation, the incumbent would enjoy extraordinarily high rents in office, but would leave the economy stuck in such a bad equilibrium that future administrations would enjoy little benefit from holding office. If instead a political compromise were forged, the incumbent would obtain lower rents today but higher rents in the future, if it returned to power. A political compromise therefore not only secures a healthier state for the economy, it also preserves some rents for future governments. Those gains from future incumbency are more relevant to political parties when they are more likely to hold power in the future. Therefore, when the government has unrestricted access to debt, curbing politicians' profligacy requires weak, not strong political turnover.

Put together, our results suggest the existence of a trilemma between intense political turnover, unrestricted government borrowing, and a political compromise that yields efficient policies. With intense political turnover and free government borrowing, a political compromise becomes unreachable. To ensure an efficient compromise under unlimited access to the public debt, political turnover must be kept in check. In turn, such a compromise can be sustained with intense turnover only when access to the public debt is sufficiently restricted. ${ }^{3}$

\footnotetext{
${ }^{3}$ We focus on a political compromise that would deliver the efficient outcome, but that does not need
} 
To convey the mechanism as clearly as possible, we make the model deliberately simple. The drawback of that simplicity is that the model abstracts from several real-world features and frictions that would be needed for a thorough empirical assessment. Such an exercise is beyond the scope of this paper. Nevertheless, despite its parsimony, the model yields an entirely novel, and potentially important, positive implication. Specifically, our analysis implies that whenever one wishes to study the economic impact of political turnover, or of fiscal constraints, one must account for the interaction between them. Interestingly, the model's main prediction is consistent with the available data, as we show in section 6 .

The paper is organized as follows. After relating our contribution to the literature in the next section, we study the relationship between political competition and economic policy, first in a model without public debt (section 3), and then allow for unrestricted public debt (section 4). Generalizing the insights from those polar cases, in section 5 we develop our main result on the tradeoff between constraints on government borrowing and limits on the number of active political parties. In section 6 we provide partial correlations among our main variables using country-level data. We conclude in section $7 .{ }^{4}$

\section{Related literature}

The impact of political institutions on economic performance has been the focus of a large body of literature. ${ }^{5}$ Yet to our knowledge the interplay between the intensity of political turnover, debt constraints and economic outcomes has not yet been analyzed. One way to understand our contribution within the existing literature is to think of our main result as a bridge between two (so far) unrelated lines of political economy research.

On one hand, the main insight from our analysis in the environment without public debt has its roots in Alesina's (1988) early study of how cooperation between two political parties that are unable to commit to policies can improve economic outcomes. Political compromises between political parties are a central feature of democratic societies. As Alesina elegantly demonstrates, while a party that follows its individually optimal policies when in power obtains a short-run gain, if both parties behave that way, economic perfor-

to be the case. In particular, in section 5.2 we carry out a similar analysis when the efficient policy is not politically viable, in which case we focus on the characterization of the best (from society's viewpoint) policy that can be sustained. The results turn out to be qualitatively analogous to those we obtain when studying the sustainability of the efficient policy.

${ }^{4}$ Proofs of all lemmas, corollaries and propositions are presented in an appendix at the end of the paper. Furthermore, an online appendix with additional and ancillary results is available at http://www.alexbcunha.com/pdfs/research/papers/ paper15oa.pdf.

${ }^{5}$ See for example the comprehensive reviews of Drazen (2000) and Persson and Tabellini (2000). 
mance suffers. With cooperation across the political spectrum, a better outcome for both parties may be achievable. ${ }^{6}$ Alesina's environment and focus are however quite different from ours. For example, in his setting political parties have different preferences and their payoffs do not depend on whether they hold office or not.

Closest to our setup without debt is the study of Acemoglu, Golosov and Tsyvinski (2011a). In their setting, political groups alternate in office according to an exogenous probabilistic process. The incumbent allocates consumption across groups, and has an incentive to increase its own welfare at the expense of others not in power. Acemoglu et al. then study how the degree of power persistence affects the possibility of cooperation among the political groups. Their main finding is that greater turnover helps to reduce political economy distortions and to sustain efficient outcomes. A similar result arises here when public debt is ruled out. Acemoglu et al. do not study, however, situations where the current policy affects the set of actions of future governments. ${ }^{7}$

Yet that is the focus of a large body of research that goes back to the seminal contributions of Persson and Svensson (1989) and Alesina and Tabellini (1990). ${ }^{8}$ A recurrent theme in that literature is the policymaking distortions created by political turnover. In particular, by making politicians less patient, turnover can induce them to over-borrow. Although the mechanism is distinct, this is also a key force in our analysis when public debt is unrestricted: incumbents are more likely to internalize the cost of over-indebtednesswhich constrains future rent-seeking - when they expect to return to office in the future. If that probability is very low, the incumbent will not internalize those costs, spend as much

\footnotetext{
${ }^{6}$ Dixit, Grossman and Gul (2000) extend Alesina's (1988) logic to a situation where the political environment evolves stochastically. As a result, the nature of the political compromise between the two parties changes over time, depending on the electoral strength of the party in office. Acemoglu, Golosov and Tsyvinski (2011b) study instead an infinitely repeated game between a self-interested politician who holds power and consumers. They show that society may be able to discipline the politician and induce him to implement the optimal taxation policy in the long run despite his self-interest, provided that the politician discounts the future as consumers do.

${ }^{7}$ Bowen and Mo (2016) obtain a similar result - that more political competition makes policies more aligned with the representative consumer - in a rather distinct environment, where politicians can commit to policies and are influenced both by lobbies and by office benefits.

${ }^{8}$ Battaglini (2014) departs from those canonical models by extending the analysis to a two-party infinite horizon problem and by explicitly modeling elections. Thus, manipulation of public debt by one party affects not only the policy space available to future governments but also electoral probabilities. Callander and Hummel (2014) show that intertemporal policy linkages can arise even if there is no state variable, provided that information about the actual outcomes of a policy is incomplete. Once the party in power decides the initial level of the policy variable, society learns the mapping between policy and outcome at that initial level. Because there is a correlation between policies and outcomes at different levels, the incumbent sometimes engages in preemptive policy experimentation, manipulating the public information in the policy-outcome space available to its successor. Bierbrauer and Boyer (2013) study the relationship between political competition and welfare, but focus on the mode of political competition. Bonomo and Terra (2010) develop a model where electoral competition is influenced by lobbies and gives rise to electoral cycles. Fiva and Natvik (2013) point out that strategic manipulation of state variables due to political turnover is not exclusive to public debt, also extending to investment in physical capital.
} 
as possible when in power, and leave the bill to whoever comes next.

Our key result links those two views by showing how the availability of debt shapes the desirability of political turnover. In contrast with the main message from Acemoglu et al. (2011a), greater turnover does not always help. Unlike what the strategic debt literature often suggests, it does not necessarily hurt either. Rather, we establish a tradeoff between intense political turnover and unrestricted access to debt. The bottom line is that political turnover has very different implications depending on the government's ability to borrowor equivalently, the desirability of a debt ceiling hinges on the level of political turnover. To our knowledge, this point has not been made before either in a formal model or informally.

This tradeoff does relate to a result by Azzimonti, Battaglini and Coate (2015), who study the impact of a balanced budget rule. They show that by constraining the tax smoothing role of the public debt, the rule induces legislators to lower the debt in the long run to prevent excessive tax volatility. Otherwise the debt would be inefficiently high due to political frictions in the legislative process, especially when agents are less patient; hence the debt reduction is more socially beneficial precisely in that case. In our analysis a tight ceiling on the debt is most desirable also when politicians become less patient, which happens when political turnover is intense. Despite the similarity, the sources of political friction, as well as the main mechanisms - restrictions on tax smoothing in the analysis of Azzimonti et al., difficulties in building a political compromise here - are entirely different in the two papers.

More fundamentally, we believe we are the first to point out that a tight debt ceiling can exacerbate political economy distortions. The prevalent view is that fiscal rules exist to mitigate distorted incentives in policymaking, providing a commitment mechanism to governments. Their cost is the resulting loss of flexibility to react to shocks. In our nonstochastic model, there is no need for flexibility. Still, a debt limit can in some cases hurt the economy by inhibiting an efficiency-enhancing political compromise. This indicates that the consequences of debt rules can be rather subtle. ${ }^{9}$

Several other authors seek to explain how political economy frictions distort policy-

\footnotetext{
${ }^{9}$ Bisin, Lizzeri and Yariv (2015) provide another rationalization for the adoption of debt ceilings and balanced budget rules. They study the interaction between voters who have time inconsistent preferences and two candidates who choose political platforms to maximize their electoral prospects. Due to the voter's time inconsistency, candidates have an incentive to propose policies that entail debt-financed transfers that will allow consumers to increase their consumption above the level that was optimal ex-ante. As a consequence, the economy will have an inefficiently high level of public debt. In contrast, Besley and Smart (2007) point out that a drawback of a debt ceiling is that it can disturb the political equilibrium and aggravate adverse selection problems. Halac and Yared (2015) take a different approach, studying the desirability of centralized versus decentralized fiscal rules in a multi-country economy, where the redistributive and the disciplining effects of interest rates play an important role.
} 
making through debt. For example, in an environment with both political turnover and economic volatility, Caballero and Yared (2010) find that rent-seeking motivations lead to excessive spending when there is high political uncertainty relative to economic uncertainty. Yet a rent-seeking incumbent will tend to underspend relative to the social planner during a boom when economic uncertainty is high relative to political uncertainty. The intuition is that an incumbent who has a high probability of keeping power will save during a boom to assure higher rents in the future, when the economy is likely to weaken. This result relates to our finding under unrestricted debt that weak political turnover promotes good economic policies because political parties want to preserve future rents in case they return to power. ${ }^{10}$ Song, Storesletten and Zilibotti (2012) study an environment where excessive levels of debt originate not from conflict between long-living political parties, but from an intergenerational conflict. Despite the very different setup, both here and in Song et al., lack of cooperation can lead to immiseration in the long run, when all governments can do is service the debt while providing the minimum level of the public good. ${ }^{11}$

The empirical literature studying the effects of political turnover on economic policies, on the other hand, is more sparse. Using data for U.S. states since the nineteenth century, Besley, Persson and Sturm (2010) find that lack of political competition is strongly associated with "bad," anti-growth, policies. In their American environment, more political competition means simply the difference between elections contested by two parties and elections won by a clearly dominant party, so in our setting this would be equivalent to moving from a single-party ("dictatorship") to a bipartisan society. Closer in spirit to our analysis, Acemoglu, Reed and Robinson (2014) explore the effects of varying degrees of local political competition in Sierra Leone, which were arguably exogenously determined by the British colonial authorities in the late nineteenth century. Acemoglu et al. find that the number of potential local political rulers ("chiefs") is positively correlated with several measures of economic development. That finding closely resembles our result in the no-debt economy, which is a good approximation for those regions, where rulers lack the ability to borrow extensively. ${ }^{12}$

\footnotetext{
${ }^{10}$ This effect also resembles a force stressed by Azzimonti (2011) when studying how polarization and political instability affects government expenditures, investment and long-run growth. She finds that a greater probability of returning to power puts a brake on the inefficiencies due to political uncertainty.

${ }^{11}$ Aizenman and Powell (1998) develop a model where conflict happens instead within the government, and the presence of competing parties in elections lowers the inefficiency of policies by disciplining incumbents.

${ }^{12}$ Arvate (2013) finds a related result when studying local governments in Brazil, which are unable to borrow freely in the market and display varying levels of political competition. There is also an empirical literature investigating the effects of political turnover on economic performance indirectly, by looking at how it affects government expenditures and the public debt. Results typically vary with methodology and sample. For example, in a panel of 19 OECD countries over the 1970-95 period, Perotti and Kontopoulos
} 
There is also a-largely unrelated - empirical literature investigating the macroeconomic impact of budget rules and fiscal rules. As Canova and Pappa (2006) point out, "the existing evidence on the issue is, at best, contradictory" (p. 1392). To some extent this may reflect lack of theoretical guidance: as Azzimonti et al. (2015, p.1) highlight, there is "remarkably little economic analysis" of the economic impact of budget rules, in contrast with the widespread policy debate on the issue. As a result, much of the empirical research focuses on the effectiveness of the rules (i.e., on whether the rules can be easily circumvented by accounting gimmicks), rather than on their economic consequences. ${ }^{13}$

Now, in none of the empirical analyses mentioned above are political turnover and fiscal constraints considered together. A very notable exception - the only one we are aware of is the recent study of the effects of fiscal restraints in Italian municipalities by Grembi, Nannicini and Troiano (2016). They exploit an arguably exogenous relaxation of fiscal rules, decided at the national level, which did not affect small cities with a population below a given threshold. Thus, they can compare municipalities just below and just above the threshold. Interestingly, Grembi et al. find that the effect of relaxing the fiscal constraint varies systematically with the number of political parties in the city council and with whether the mayor can run for reelection. In particular, they find that relaxing the fiscal constraint induces a deficit bias, but only in municipalities where political competition is sufficiently intense. Although their study is not designed to test a specific model, the results point to sizeable interaction effects between the consequences of fiscal restraints and the degree of political competition, precisely in the direction predicted by our model.

\section{A society without public debt}

To facilitate exposition and gain intuition, we start our analysis with the simplest possible environment. Hence, in this section we assume that the government does not have access to public debt and, as a consequence, needs to balance its budget in every period. In the next section we study the opposite polar case in which the government can borrow without

(2002) find that larger coalition sizes in power (a proxy for the instability of the government) are associated with more public expenditures and deficits, but Ricciuti (2004) finds no evidence that faster turnaround in office leads to more government consumption and higher public debt. Similarly, Pettersson-Lidbom (2001) finds that among Swedish municipalities a higher probability of political turnover induces rightwing incumbents to accumulate debt, but leads left-wing ones to lower the debt.

${ }^{13}$ Milesi-Ferretti (2003) studies theoretically the conditions under which "creative accounting" can undermine the effectiveness of fiscal rules. A related literature analyzes the effects of different debt levels on economic performance. See for example Reinhart and Rogoff (2010) and Checherita-Westphal and Rother (2012). 
any legal constraint. In section 5 we then move to the general case where the public debt is bounded by a legal ceiling that encompasses the polar cases of no debt (as in this section) and unrestricted debt (as in the next section) but also all the intermediate cases.

\subsection{The economic environment}

There is a continuum of identical households with Lebesgue measure one. Each of them is endowed with one unit of time. A single competitive firm produces a homogenous good under constant returns to scale. Technology is described by $0 \leq c+g \leq l$, where $l$ is the amount of time allocated to production, $c$ corresponds to household consumption, and $g$ denotes a publicly provided good. At each date $t$, feasibility requires

$$
c_{t}+g_{t}=l_{t}
$$

A spot market for goods and labor services operates in every period. The government finances its expenditures by taxing labor income at a proportional rate $\tau_{t}$. This tax rate is bounded above by a number $\bar{\tau}<1 .{ }^{14}$ Since in this section we assume there is no public debt, the government's budget constraint is simply

$$
g_{t}=\tau_{t} l_{t}
$$

The twice differentiable function $u=u(c, l, g)$ describes the typical household period utility function. It is strictly increasing in $c$ and $g$ and strictly decreasing in $l$. For a fixed $g, u$ satisfies standard monotonicity, concavity, and Inada conditions. Each household is endowed with one unit of time per period. Intertemporal preferences are described by

$$
\sum_{t=0}^{\infty} \beta^{t} u\left(c_{t}, l_{t}, g_{t}\right),
$$

where $\beta \in(0,1)$. A household's date- $t$ budget constraint is

$$
c_{t} \leq\left(1-\tau_{t}\right) l_{t}
$$

Given $\left\{g_{t}, \tau_{t}\right\}_{t=0}^{\infty}$, at date $t=0$ a household chooses a sequence $\left\{c_{t}, l_{t}\right\}_{t=0}^{\infty}$ to maximize (3) subject to (4) and $l_{t} \leq 1$. Let us then define a competitive equilibrium in our economy.

\footnotetext{
${ }^{14}$ The bound $\bar{\tau}$ has the role of preventing the government from driving the household utility to $-\infty$ in the policy games we consider. Without that restriction, any policy could be an equilibrium outcome.
} 
Definition $1 A$ competitive equilibrium is a sequence $\left\{c_{t}, l_{t}\right\}_{t=0}^{\infty}$ that satisfies (1) and solves the typical household's problem for given $\left\{g_{t}, \tau_{t}\right\}_{t=0}^{\infty}$.

We say that a list of sequences $\left\{g_{t}\right\}_{t=0}^{\infty},\left\{\tau_{t}\right\}_{t=0}^{\infty},\left\{c_{t}\right\}_{t=0}^{\infty}$ and $\left\{l_{t}\right\}_{t=0}^{\infty}$ is attainable if $\left\{c_{t}, l_{t}\right\}_{t=0}^{\infty}$ is a competitive equilibrium for that specific $\left\{g_{t}, \tau_{t}\right\}_{t=0}^{\infty}$.

Let us now characterize the set of attainable allocations and policies. The household's first-order necessary and sufficient conditions are (4) taken as equality and

$$
-\frac{u_{l}\left(c_{t}, l_{t}, g_{t}\right)}{u_{c}\left(c_{t}, l_{t}, g_{t}\right)}=1-\tau_{t},
$$

which is equivalent to

$$
\tau_{t}=1+\frac{u_{l}\left(c_{t}, l_{t}, g_{t}\right)}{u_{c}\left(c_{t}, l_{t}, g_{t}\right)}
$$

Combining this expression with (2), we have that any attainable outcome $\left\{g_{t}, \tau_{t}, c_{t}, l_{t}\right\}_{t=0}^{\infty}$ must satisfy

$$
g_{t}=\left[1+\frac{u_{l}\left(c_{t}, l_{t}, g_{t}\right)}{u_{c}\left(c_{t}, l_{t}, g_{t}\right)}\right] l_{t} .
$$

We can then use techniques similar to those in Chari and Kehoe (1999) to show that a list of sequences $\left\{g_{t}\right\}_{t=0}^{\infty},\left\{\tau_{t}\right\}_{t=0}^{\infty},\left\{c_{t}\right\}_{t=0}^{\infty}$ and $\left\{l_{t}\right\}_{t=0}^{\infty}$ satisfies (1) and (6) if and only if it is attainable.

At each date $t$, there are two fiscal variables $\left(g_{t}\right.$ and $\left.\tau_{t}\right)$ that the government can select. In general, there may be multiple tax rates that fund the same level of government expenditures. Yet for the sake of simplicity we want to turn the choice of a date- $t$ fiscal policy into a unidimensional problem. Thus, for each attainable value of $g$, we define $U(g)$ according to

$$
U(g) \equiv \max _{(c, l)} u(c, l, g)
$$

subject to (1) and (6). Hence, whenever we say that a sequence $\left\{g_{t}\right\}_{t=0}^{\infty}$ is a policy, we are assuming that $\tau_{t}$ is the solution of (7) for the corresponding $g_{t}$. Observe that $U$ resembles an indirect utility function; it reflects the tradeoff between the provision and the funding of $g$.

Under standard Inada conditions on households' preferences, it may happen that $U(0)=$ $-\infty$ or $U(1)=-\infty$. Such unboundedness of $U$ would lead to a severe but uninteresting problem of equilibrium multiplicity in the games we study. To prevent that, we assume that $g$ is bounded from below by a small positive number $\gamma$ and from above by a num- 
ber $\Gamma$ smaller than one. ${ }^{15}$ These bounds can be easily rationalized. Since the economy's maximum output is one, to achieve $g=1$ the government would need to tax all income while households choose to devote all their available time to work despite the $100 \%$ tax. An upper bound on $g$ below one is therefore a natural consequence of the limits on the government's ability to raise taxes. The lower bound $\gamma$ can be understood as the value that the public expenditures would take if the state were downsized to the minimum dimension allowed by law, since even such a minimalist entity would entail some expenditures.

We assume that $U$ is strictly concave, twice differentiable, and attains a maximum at a point $g^{*} \in(\gamma, \Gamma)$. We call $g^{*}$ the efficient policy. ${ }^{16}$ Inspection of problem (7) shows that the second derivative of $U$ depends on the third derivatives of $u$. Thus, unless extra assumptions are placed on $u$, one cannot ensure that $U$ is strictly concave. But it is easy to provide conventional examples in which $U$ is indeed strictly concave.

Example 1 Suppose that

$$
u(c, l, g)=a_{1} \ln c+a_{2} \ln (1-l)+a_{3} \ln g,
$$

where $a_{1}, a_{2}$, and $a_{3}$ are positive numbers. The solution of the typical household problem is given by

$$
l=\frac{a_{1}}{a_{1}+a_{2}}
$$

and

$$
c=(1-\tau) \frac{a_{1}}{a_{1}+a_{2}} .
$$

In such a context, problem (7) becomes very simple. Together, (2) and (9) imply that $\tau=g\left(a_{1}+a_{2}\right) / a_{1}$. Combine this equality with (10) to conclude that

$$
c=\frac{a_{1}}{a_{1}+a_{2}}-g .
$$

\footnotetext{
${ }^{15}$ Although this will become clearer after we describe the games played by the political parties, it is easy to see why such a restriction rules out a large family of uninteresting equilibria. Consider the upper bound $\Gamma$. Since $U(1)=-\infty$, if $g=1$ at some date, then the household lifetime utility will be equal to $-\infty$. Hence, as long as political parties care to any extent about household welfare, trigger strategies that specify reversion to the policy $g=1$ could support any policy as an equilibrium outcome in an infinitely repeated game. Similar reasoning justifies the introduction of the lower bound $\gamma$. An alternative to the introduction of the bounds $\gamma$ and $\Gamma$ consists of assuming that both $U(0)$ and $U(1)$ are larger than $-\infty$.

${ }^{16}$ Lump-sum taxes are not available. Thus, $g^{*}$ is efficient in a second-best sense; that is, in the terminology of the optimal fiscal and monetary policy literature, $g^{*}$ is a Ramsey policy. Had we allowed for lump-sum taxes, $g^{*}$ would be a Pareto efficient policy.
} 
Plug (9) and (11) into (8). This procedure leads to ${ }^{17}$

$$
U(g)=a_{1} \ln \left[a_{1}-\left(a_{1}+a_{2}\right) g\right]+a_{3} \ln g+\ln \left[\frac{a_{2}^{a_{2}}}{\left(a_{1}+a_{2}\right)^{a_{1}+a_{2}}}\right] .
$$

Therefore,

$$
U^{\prime \prime}(g)=-\left\{\frac{a_{1}\left(a_{1}+a_{2}\right)^{2}}{\left[a_{1}-\left(a_{1}+a_{2}\right) g\right]^{2}}+\frac{a_{3}}{g^{2}}\right\}<0 .
$$

All that said, what we really need to take from this subsection is the function $U$ and its properties. In short, $U$ measures the utility that the typical household achieves in a competitive equilibrium. The economics underlying its properties is simple: households enjoy an increase in $g$, but this comes at the cost of higher taxes. Thus, $U$ captures the tradeoff between the provision of $g$ and its funding, concisely describing households' preferences over consumption, leisure and the public good.

\subsection{The political environment}

A political party is a coalition of agents ("politicians") who want to achieve power to enjoy some extra utility/rents while in office. The set of all politicians has measure zero. There is an exogenous natural number $n \geq 2$ of competing and identical political parties. We denote the set $\{1,2, \ldots, n\}$ of political parties by $\mathcal{I}$ and use the letter $i$ to denote a generic party in $\mathcal{I}$. We refer to the party that holds power in period $t$ as $p_{t}$. We denote by $\mathcal{O}_{t}$ the set of opposition parties, i.e., the difference $\mathcal{I}-\left\{p_{t}\right\}$.

The period preferences of party $i$ are described by

$$
V_{i}\left(g_{t}\right)=U\left(g_{t}\right)+\mathbf{1}_{i t} \lambda g_{t}
$$

where $\lambda>0$ and $\mathbf{1}_{i t}$ is an indicator function taking the value of one when party $i$ is in office and zero otherwise. The incumbent party cares about both the welfare of households and government expenditures, from which it extracts rents; parameter $\lambda$ describes the additional weight that the incumbent places on $g$ relative to consumers. In contrast, the interests of opposition parties and households are perfectly aligned, since $\mathbf{1}_{i t}=0$ for all $i \in \mathcal{O}_{t}$ and, as a consequence, the payoff of each of those agents is equal to $U\left(g_{t}\right)$.

We adopt this specific representation for simplicity. The feature of (14) that really

\footnotetext{
${ }^{17}$ Notice that the expression inside the first $\log$ in $(12)$ is positive. To see that, observe that equality (10) ensures that $c>0$; combine this fact with (11) to establish that $a_{1}-\left(a_{1}+a_{2}\right) g>0$.
} 
matters is that political parties perceive a higher relative benefit from public expenditures when in power than when out of power.

There are at least two possible ways of interpreting the term $\lambda g$. The first is to understand it as ego rents that increase as the government consumption grows. The second is to interpret it as extra income (e.g., through corruption) that a politician can obtain from public spending. The opportunities to enjoy those additional gains increase with the level of public expenditures.

It is useful to define a benchmark where there is no political turnover, which is equivalent to having $n=1$. In this case, the function

$$
V(g)=U(g)+\lambda g
$$

corresponds to the period payoff of the everlasting ruling party. We define the maximizer $g^{D}$ of $V(g)$ as the dictatorial policy. Since $g$ must lie in the set $[\gamma, \Gamma], g^{D}$ satisfies $U^{\prime}\left(g^{D}\right) \geq-\lambda$; this condition holds with equality whenever $g^{D}<\Gamma$. Clearly, $g^{D}>g^{*}$, so a dictator overspends relative to the social optimum. Moreover, $g^{D}$ is strictly increasing in $\lambda$ whenever $g^{D}<\Gamma$. Thus, $\lambda$ reflects the political parties' degree of profligacy, in the sense that an incumbent that does not strategically interact with other political parties sets $g=g^{D}$ and the difference $g^{D}-g^{*}$ is increasing in $\lambda$.

Political parties cannot commit to specific policies. Furthermore, they share the same preferences before knowing which of them will hold office. As our focus is on the intertemporal coordination of policies between current and future governments, we assume that an election is simply a randomizing device that, at the beginning of each period, selects party $i$ to govern during that period with probability $\pi_{i}(n) \geq 0$, where $\sum_{i \in \mathcal{I}} \pi_{i}(n)=1$ and $d \pi_{i}(n) / d n<0 .{ }^{18}$ For analytical convenience, and with little additional loss of generality, we assume further that $\pi_{i}(n)=1 / n$ for all $i \in \mathcal{I}$, so that all parties are equally popular.

We define units so that each period of time corresponds to an administration term. The lifetime payoff of a political party is the discounted sum of its period payoffs: $\sum_{t=0}^{\infty} \beta^{t} V_{i}\left(g_{t}\right)$.

Our model is fully characterized by the array $(\beta, U, \gamma, \Gamma, \lambda, n)$. Its first four components are purely economic factors, while the last two are political ones. Hence, we say that $(\beta, U, \gamma, \Gamma)$ is an economy and $(\lambda, n)$ is a polity. We use the term society to denote a combination of an economy and a polity - that is, the entire array $(\beta, U, \gamma, \Gamma, \lambda, n)$.

We finish this subsection with a brief discussion of some features of the model. We

\footnotetext{
${ }^{18}$ Similar exogenous rules determining which party selects policies at each point in time have been used by several other authors, starting with Baron and Ferejohn (1989).
} 
will see that parameter $n$ plays a pivotal role in the analysis. We will recurrently refer to $n$ as our measure of "political turnover," and carry out comparative statics exercises accordingly. ${ }^{19}$ Now, although in the model $n$ measures simultaneously the number of political parties and the reciprocal of the probability that the incumbent will hold power in the future, the latter is its key role, proxying the degree of "power persistence" in the polity. It follows that the assumption that $\pi_{i}(n)=1 / n$ can be relaxed. For example, one could generalize the analysis to heterogeneous $\pi_{i}$, so features such as incumbency advantage could be considered. Although this would entail the cost of introducing a taxonomy, it would not yield fundamentally different insights, provided that $d \pi_{i}(n) / d n<0$.

It is worth noting that our key assumptions are rather standard. They are very similar, for example, to those of Aguiar and Amador (2011) in their analysis of investment and growth patterns when governments can expropriate foreign capital. Like here, their political friction stems from a situation where incumbents enjoy a higher payoff from government consumption than non-incumbents, governments do not have access to a commitment technology, and political turnover is exogenous. ${ }^{20}$

\subsection{The policy game}

To study how political competition impacts policymaking, we consider a game in which the players are the political parties. The incumbent party selects current policies. Future policies are chosen by future governments.

Let $h^{t}=\left(g_{0}, g_{1}, \ldots, g_{t}\right)$ be a history of policies. At each date $s$, the incumbent $p_{s}$ selects a date-s policy $g_{s}$ as a function of history $h^{s-1}$. We denote that choice by $\sigma_{p, s}\left(h^{s-1}\right)$. The incumbent also chooses plans $\left\{\sigma_{p, t}\right\}_{t=s+1}^{\infty}$ for future policies in case it later returns to office. An opposition party $o$ selects only plans $\left\{\sigma_{o, t}\right\}_{t=s+1}^{\infty}$ for future policies. Given an array $\left[\left\{\sigma_{i, t}\right\}_{t=0}^{\infty}\right]_{i \in \mathcal{I}}$ of policy plans and a history $h^{t-1}$, the date- $t$ policy follows the rule

$$
g_{t}=\sum_{i \in \mathcal{I}} \mathbf{1}_{i t} \sigma_{i, t}\left(h^{t-1}\right)
$$

That is, the actual policy $g_{t}$ is the choice of $g$ for period $t$ of the incumbent in period $t$.

\footnotetext{
${ }^{19}$ This is in line, for example, with the interpretation of Bowen and Mo (2016) of $n$ as the degree of political competition in the polity.

${ }^{20}$ A similar observation applies to Azzimonti (2011), whose setup also features government and society having different objectives, with the former being unable to commit to policies.
} 
The realized lifetime payoff $\mathcal{V}_{i, s}$ of party $i$ from date $s$ onward is given by

$$
\mathcal{V}_{i, s}=\sum_{t=s}^{\infty} \beta^{t-s} V_{i}\left(g_{t}\right)
$$

Observe that $V_{i}($.$) incorporates the possibility of being in power or not. The incumbent's$ problem is the following. Given $h^{s-1}$ and the other parties' plans, $\left[\left\{\sigma_{o, t}\right\}_{t=s+1}^{\infty}\right]_{o \in \mathcal{O}_{s}}$, it chooses a policy plan $\left\{\sigma_{p, t}\right\}_{t=s}^{\infty}$ to maximize the expected value $E\left(\mathcal{V}_{p, s}\right)$. Opposition parties solve an analogous problem.

Given the ex-ante symmetry of political parties, it is natural to concentrate on symmetric outcomes.

Definition $2 A$ symmetric political equilibrium is a policy plan $\left\{\sigma_{t}\right\}_{t=0}^{\infty}$ with the property that, if all opposition parties follow the policy plan $\left\{\sigma_{t}\right\}_{t=0}^{\infty}$, then the solution of the incumbent's problem at every period s for all histories $h^{s-1}$ is $\left\{\sigma_{t}\right\}_{t=s}^{\infty}$. A sequence $\left\{g_{t}\right\}_{t=0}^{\infty}$ is a symmetric political outcome if there exists a symmetric political equilibrium $\left\{\sigma_{t}\right\}_{t=0}^{\infty}$ such that $\sigma_{t}\left(g_{0}, \ldots, g_{t-1}\right)=g_{t}$ for all $t$.

The symmetric political equilibrium is similar to the sustainable equilibrium introduced by Chari and Kehoe (1990). As those authors point out, such an equilibrium entails subgame perfection.

It is easy to see that $g_{t}=g^{D}$ in every $t$ is a symmetric political outcome. Define the dictatorial plan $\left\{\sigma_{t}^{D}\right\}_{t=0}^{\infty}$ so that, after any history $h^{t-1}$, every political party sets $g_{t}=g^{D}$ if it holds power. Suppose that, at some date $t$, party $p_{t}$ believes that all parties in $\mathcal{O}_{t}$ will follow the plan $\left\{\sigma_{t}^{D}\right\}_{t=0}^{\infty}$. Clearly, the best course of action for $p_{t}$ is to implement $\left\{\sigma_{t}^{D}\right\}_{t=0}^{\infty}$ as well. Therefore, $\left\{\sigma_{t}^{D}\right\}_{t=0}^{\infty}$ is a symmetric political equilibrium, yielding $g_{t}=g^{D}$ for all $t$.

Having identified an equilibrium for the policy game, we use trigger strategies to characterize other symmetric political outcomes. In particular, we consider a revert-todictatorship policy plan. That plan specifies that if all previous governments implemented a certain policy $\left\{g_{t}\right\}_{t=0}^{\infty}$, then the current incumbent does the same; otherwise, the incumbent implements $g=g^{D}$ today and whenever it returns to office.

The revert-to-dictatorship threat is appealing because the dictatorial equilibrium is the only equilibrium that does not involve any coordination among the political parties, in the sense that the player in office chooses the action that maximizes its period payoff. Furthermore, the dictatorial equilibrium has the nice property that, in a finite version of 
our game, the only subgame perfect equilibrium would entail playing the dictatorial policy in every period.

Denote by $\Omega_{s}\left(\left\{g_{t}\right\}_{t=s}^{\infty}\right)$ the expected value of $\mathcal{V}_{p, s}$ when all parties follow the policy $\left\{g_{t}\right\}_{t=0}^{\infty}$. Thus,

$$
\Omega_{s}\left(\left\{g_{t}\right\}_{t=s}^{\infty}\right)=U\left(g_{s}\right)+\lambda g_{s}+\sum_{t=s+1}^{\infty} \beta^{t-s}\left[U\left(g_{t}\right)+\frac{\lambda}{n} g_{t}\right]
$$

With some abuse of notation, let $\Omega(g)$ represent the payoff of party $i$ when $g_{t}=g$ for all $t$ :

$$
\Omega(g)=\frac{1}{1-\beta}\left[U(g)+\left(1-\beta+\frac{\beta}{n}\right) \lambda g\right]
$$

Then, if a policy $\left\{g_{t}\right\}_{t=0}^{\infty}$ satisfies

$$
\Omega_{s}\left(\left\{g_{t}\right\}_{t=s}^{\infty}\right) \geq \Omega\left(g^{D}\right)
$$

for every date $s,\left\{g_{t}\right\}_{t=0}^{\infty}$ is a symmetric political outcome. The left-hand side of (15) is the payoff of the date- $s$ incumbent if $\left\{g_{t}\right\}_{t=0}^{\infty}$ is chosen from date $s$ onward, while the right-hand side corresponds to its payoff if the dictatorial policy is selected from date $s$ onward.

To see that (15) is a sufficient condition for $\left\{g_{t}\right\}_{t=0}^{\infty}$ to constitute a symmetric political outcome, suppose that all parties in $\mathcal{O}_{s}$ follow the revert-to-dictatorship plan associated with $\left\{g_{t}\right\}_{t=s}^{\infty}$. Consider the decision of party $p_{s}$ at some date $s$. If the prevailing history is $\left\{g_{t}\right\}_{t=0}^{s-1}$, then condition (15) ensures that choosing $g_{t}$ is optimal for party $p_{s}$. If the prevailing history differs from $\left\{g_{t}\right\}_{t=0}^{s-1}$, then all parties in $\mathcal{O}_{s}$ set $g=g^{D}$ whenever they hold power. Consequently, the best action for party $p_{s}$ is to implement $g=g^{D}$ as well. Hence, the revert-to-dictatorship plan is a best-response strategy for party $p_{s} .{ }^{21}$

\subsection{The political feasibility of the efficient policy}

Politicians can do better than just follow the dictatorial policy if they coordinate policies, i.e., if they forge a political compromise. We now assess the conditions under which a political compromise can sustain the efficient policy.

\footnotetext{
${ }^{21}$ Observe that (15) is a sufficient condition for a policy to be an equilibrium outcome. We cannot rule out that, by designing different punishments, it may be possible to implement policies that do not satisfy (15). Since solving this specific question will add little to the comprehension of the problems we deal with here, we do not address this matter in this paper.
} 
If $g_{t}=g^{*}$ for every $t,(15)$ becomes $\Omega\left(g^{*}\right) \geq \Omega\left(g^{D}\right)$. This inequality is equivalent to

$$
\frac{\beta}{1-\beta}\left[U\left(g^{*}\right)-U\left(g^{D}\right)+\frac{\lambda}{n}\left(g^{*}-g^{D}\right)\right] \geq V\left(g^{D}\right)-V\left(g^{*}\right) .
$$

Therefore, the efficient policy is a symmetric political outcome if (16) holds. Its left-hand side represents the present value of the future gains from cooperation for the incumbent, whereas the right-hand side denotes its short-run gain from implementing the dictatorial policy instead of the efficient one.

Here we should stress that our analysis has an important feature that distinguishes it from the approach usually adopted in the study of infinitely repeated games. In our environment, the payoff of consumers - according to which the efficient policy is defineddoes not correspond to the payoff of the politicians - the players of the game. Such a distinction is natural in our context, but has important implications. Specifically, here a high enough $\beta$ does not ensure the sustainability of efficient policies. To see that, note from the definitions of $g^{*}$ and $g^{D}$ that $V\left(g^{D}\right)-V\left(g^{*}\right)>0, U\left(g^{*}\right)-U\left(g^{D}\right)>0$ and $(\lambda / n)\left(g^{*}-g^{D}\right)<0$. Thus, the right-hand side of (16) is strictly positive but its lefthand side may be negative. In particular, for $\lambda$ sufficiently large the left-hand side will be negative regardless of $\beta$. Therefore, the sustainability of the efficient policy is not ensured even when the intertemporal discount factor is arbitrarily close to one.

Now, for given $\beta$, the number of political parties plays a critical role for the sustainability of the efficient policy. The gains from cooperation for the incumbent come from deterring excessive public spending when it is not enjoying rents from those expenditures. When the incumbent expects to hold office often, those circumstances are relatively rare and its gain from cooperation can become negative.

It helps to break down the analysis of (16) into two cases. We study each of them in turn. Suppose first that

$$
\frac{\beta}{1-\beta}\left[U\left(g^{*}\right)-U\left(g^{D}\right)\right] \leq V\left(g^{D}\right)-V\left(g^{*}\right)
$$

Since $(\lambda / n)\left(g^{*}-g^{D}\right)<0$, inequality (16) would not hold for any $n$. This happens when a high $\lambda$ makes the short-run gain from implementing $g^{D}$ too large relative to the future gains under coordination. In this case, the efficient policy is unachievable through the revert-to-dictatorship strategy. Proposition 1 formalizes this claim. ${ }^{22}$

\footnotetext{
${ }^{22}$ The proofs of all propositions, lemmas and corollaries are presented in an appendix at the end of the paper.
} 
Proposition 1 For every economy $(\beta, U, \gamma, \Gamma)$, there exists a number $\lambda_{0}$ such that, if a polity $(\lambda, n)$ satisfies $\lambda \geq \lambda_{0}$, then inequality (17) holds. As a result, the efficient policy $g^{*}$ cannot be implemented by the revert-to-dictatorship strategy for any level of $n$.

Consider now the case in which (17) does not hold:

$$
\frac{\beta}{1-\beta}\left[U\left(g^{*}\right)-U\left(g^{D}\right)\right]>V\left(g^{D}\right)-V\left(g^{*}\right)
$$

It is then possible to place conditions on $n$ that ensure that (16) holds and, as a consequence, the efficient policy constitutes a symmetric political outcome. Define

$$
N^{0}(\beta, \lambda) \equiv \frac{\lambda\left(g^{*}-g^{D}\right)}{\frac{1-\beta}{\beta}\left[V\left(g^{D}\right)-V\left(g^{*}\right)\right]-\left[U\left(g^{*}\right)-U\left(g^{D}\right)\right]} .
$$

This is the value of $n$ that satisfies (16) with equality. Clearly, $N^{0}(\beta, \lambda)>0$ under (18).

Proposition 2 If a society $(\beta, U, \gamma, \Gamma, \lambda, n)$ satisfies (18) and $n \geq N^{0}(\beta, \lambda)$, then the efficient policy $g^{*}$ constitutes a symmetric political outcome.

According to Proposition $2, N^{0}(\beta, \lambda)$ defines the minimum number of parties that can sustain $g^{*}$ as an equilibrium with the revert-to-dictatorship plan. Thus, if the efficient policy is sustainable in a polity $(\lambda, n)$, it is also sustainable in a polity $\left(\lambda, n^{\prime}\right)$ where $n^{\prime}>n$. In that sense, a high $n$ can offset the inefficiencies engendered by the political friction by fostering a political compromise.

Summing up, when the actions of the political party in office have no bearing on the options available to future governments, there is a clear sense in which more political turnover can foster the implementation of better policies and improve economic performance. As we will see, this is no longer necessarily true when current policies can affect the set of actions available to future governments.

\section{A society with unrestricted public debt}

In this section we study the polar case in which the government can borrow without any legal constraint. As we will see, this critically changes the results. Together, the analysis of this section and the analysis under no debt in section 3 lay out the technical details and the key intuition for the study of a generic debt limit in the next section. 
We want to introduce the public debt in the model of section 3 without compromising tractability. A simple way to achieve that is to consider a small open economy in which the government has access to the international financial market. This allows us to keep working with a period- $t$ indirect utility function $U(\cdot)$ that maps economic policies into household welfare in a competitive equilibrium. Recall that in section 3 that function reflects the tradeoff between the provision of the public good and its funding. With the introduction of public debt, the tradeoff now involves providing the public good, raising distortionary tax revenues, and managing the public debt. ${ }^{23}$ Accordingly, in this section we represent the payoff of a typical household by a function $U\left(b_{t}, g_{t}, b_{t+1}\right)$, where $b_{t}$ denotes the beginning-of-period $t$ value of the public debt, and where the interest rate (exogenous from the perspective of the country) is a built-in component of $U$.

\subsection{The economic environment}

\subsubsection{Basic economic structure and competitive equilibrium}

We consider now an open-economy version of the model presented in subsection 3.1. As before, there is a single good. Technology and feasibility are described by

$$
c_{t}+g_{t}+x_{t}=l_{t}
$$

where $x$ denotes the amount exported. If $x$ is negative, then the country is importing the good. The problem of the households is just as before.

The government has access to a foreign financial market where it can buy and sell claims to one unit of the consumption good, redeemable in the next period. Let $b_{t}$ denote the amount of government-issued claims outstanding at the beginning of period $t$, measured in the same units as $g_{t}$. To make the notation lighter, we set its initial value $b_{0}$ to zero. Those claims are traded at a price $q_{t}$. Since this is a small open economy, the interest rate is taken as given, and so is $q_{t}$. Following a standard assumption in international macroeconomics, we assume that $q_{t}=\beta$. Hence, the government period budget constraint is

$$
g_{t}+b_{t}=\tau_{t} l_{t}+\beta b_{t+1} .
$$

\footnotetext{
${ }^{23}$ The results of section 3 do not depend on whether or not the government has access to lump-sum taxes. However, we know since Barro (1974) that if lump-sum taxes are available, the government can relax any constraint imposed by the public debt by simply raising tax revenues that exactly match the value of its outstanding bonds. Therefore, lump-sum taxes are ruled out in the underlying economy.
} 
We rule out the possibility of government default. Thus, to avoid Ponzi schemes, the government debt must satisfy the constraint $\left|b_{t+1}\right| \leq M<\infty$, where $M$ is large enough so that this constraint never binds.

Definition $3 A$ competitive equilibrium is a sequence $\left\{c_{t}, l_{t}, x_{t}\right\}_{t=0}^{\infty}$ that satisfies (19) and (20) and solves the typical household's problem for given $\left\{g_{t}, \tau_{t}, b_{t+1}\right\}_{t=0}^{\infty}$.

We say that a list of sequences $\left\{g_{t}\right\}_{t=0}^{\infty},\left\{\tau_{t}\right\}_{t=0}^{\infty},\left\{b_{t+1}\right\}_{t=0}^{\infty},\left\{c_{t}\right\}_{t=0}^{\infty},\left\{l_{t}\right\}_{t=0}^{\infty}$ and $\left\{x_{t}\right\}_{t=0}^{\infty}$ is attainable if $\left\{c_{t}, l_{t}, x_{t}\right\}_{t=0}^{\infty}$ is a competitive equilibrium for that specific $\left\{g_{t}, \tau_{t}, b_{t+1}\right\}_{t=0}^{\infty}$.

We now turn to the problem of characterizing the set of attainable sequences. By combining (4) taken as equality with (19) and (20), we obtain

$$
x_{t}+\beta b_{t+1}-b_{t}=0 .
$$

This expression reflects the balance of payments of this economy. Hence, a competitive equilibrium satisfies (4) taken as equality, (5), (19) and (21). Let $H(c, l, g) \equiv u_{c}(c, l, g) c+$ $u_{l}(c, l, g) l$. Using the reasoning of Chari and Kehoe (1999), it is easy to show that the set of attainable sequences is characterized by (19),

$$
H\left(c_{t}, l_{t}, g_{t}\right)=0
$$

and

$$
\sum_{t=0}^{\infty} \beta^{t} x_{t}=0 .
$$

These three conditions constrain only the sequences $\left\{c_{t}\right\}_{t=0}^{\infty},\left\{l_{t}\right\}_{t=0}^{\infty},\left\{g_{t}\right\}_{t=0}^{\infty}$ and $\left\{x_{t}\right\}_{t=0}^{\infty}$. Given these four sequences, $\left\{b_{t+1}\right\}_{t=0}^{\infty}$ must satisfy

$$
\sum_{s=t+1}^{\infty} \beta^{s-(t+1)} x_{s}=b_{t+1}
$$

while $\left\{\tau_{t}\right\}_{t=0}^{\infty}$ is given by (5).

The efficient allocation $\left\{c_{t}^{*}, l_{t}^{*}, g_{t}^{*}, x_{t}^{*}\right\}_{t=0}^{\infty}$ solves the problem of maximizing households' lifetime utility (3) subject to (19), (22) and (23). We have the following result.

Lemma 1 The efficient allocation and its underlying policy have the properties that $g_{t}^{*}$ is constant over time, $x_{t}^{*}=0$, and $b_{t+1}^{*}=0$. 
Our environment does not have any exogenous or stochastic disturbances, so there is no role for the tax smoothing property of the public debt. As a consequence, despite the possibility of borrowing, the efficient policy and allocation are time-invariant.

\subsubsection{The constraints on the government's choices}

Before carrying out our analysis, we need to specify the action space of the government when it can issue debt. The sequence of period budget constraints (20) is the path through which the date- $t$ incumbent impacts the set of admissible actions of future administrations. To represent its relevant features in a simple way and provide a convenient representation of the action space of the date- $t$ incumbent, we use two very generic functions, $f^{b}\left(b_{t}\right)$ and $\Gamma\left(b_{t}, b_{t+1}\right)$.

Definition 4 The function $f^{b}\left(b_{t}\right)$ specifies, for given $b_{t}$, the value of $b_{t+1}$ that results from the government's budget constraint when the difference between tax revenue and government expenditures is at its maximum attainable value.

Thus, $f^{b}\left(b_{t}\right)$ defines the minimum attainable value for $b_{t+1}$. It reflects how the economic constraints on the ability of the government to raise taxes place a limit on how much it could reduce the public debt. Let $\bar{B}>0$ denote the maximum value that the debt can reach at any given date. By definition, $\bar{B}$ is such that the corresponding interest service equals the maximum attainable fiscal surplus. Thus, in general the date- $t$ government's choice of $b_{t+1}$ must satisfy

$$
b_{t+1} \in\left[f^{b}\left(b_{t}\right), \bar{B}\right] .
$$

Clearly, $f^{b}($.$) must be strictly increasing. Hence, a higher b_{t}$ shrinks the set $\left[f^{b}\left(b_{t}\right), \bar{B}\right]$. In particular, $f^{b}(\bar{B})=\bar{B}$ : if the debt ever reaches $\bar{B}$, the economy becomes permanently locked in a state of high debt and low government consumption, in the sense that $b_{t+1}=\bar{B}$ implies that $\left(g_{s}, b_{s+1}\right)=(\gamma, \bar{B})$ for every $s \geq t+1$. In principle, the debt could take negative values. We assume that the ability of the rest of the world to repay such a debt is also bounded, so there is a real number $\underline{B} \geq 0$ such that $b_{t+1} \geq-\underline{B}$ for all $t$. For convenience, we also assume that $f^{b}($.$) is continuously differentiable.$

Definition 5 The function $\Gamma\left(b_{t}, b_{t+1}\right)$ specifies, for given $b_{t}$ and $b_{t+1}$, the value of $g_{t}$ that results from the government's budget constraint when tax revenue is at its maximum attainable value. 
Thus, $\Gamma\left(b_{t}, b_{t+1}\right)$ defines the maximum attainable value for $g_{t} \cdot{ }^{24}$ It reflects how the economic constraints on the ability of the government to raise taxes place a limit on how much it can spend. Thus, in general the date- $t$ government's choice of $g_{t}$ must satisfy

$$
g_{t} \in\left[\gamma, \Gamma\left(b_{t}, b_{t+1}\right)\right]
$$

Clearly, $\Gamma($.$) must be strictly decreasing in b_{t}$ and strictly increasing in $b_{t+1}$. Hence, either a higher $b_{t}$ or a lower $b_{t+1}$ shrinks the set $\left[\gamma, \Gamma\left(b_{t}, b_{t+1}\right)\right]$. In particular, since $\gamma$ is the only admissible value for $g_{t}$ when $b_{t}=\bar{B}, \Gamma(\bar{B}, \bar{B})=\gamma$. Furthermore, suppose that $b_{t}$ is equal to some generic value $b$ for every $t$. The higher $b$ is, the higher the interest the government must pay, and the tighter its budget constraint becomes. Hence, denoting the partial derivatives of $\Gamma$ with respect to $b_{t}$ and $b_{t+1}$ by, respectively, $\Gamma_{b}$ and $\Gamma_{b^{\prime}}$, they must satisfy

$$
\Gamma_{b}(b, b)+\Gamma_{b^{\prime}}(b, b)<0 .
$$

For convenience, we also assume that $\Gamma($.$) is continuously differentiable.$

In sum, the date- $t$ incumbent can increase the end-of-period debt $b_{t+1}$ to enlarge the set from which $g_{t}$ is selected. However, that would restrict the choices $\left(g_{t+1}, b_{t+2}\right)$ of the next administration by tightening the sets (25) and (26) at date $t+1$. In the limiting case in which $b_{t+1}=\bar{B}$, the date- $t$ incumbent permanently locks the society in state $(\gamma, \bar{B})$.

\subsubsection{The function $U\left(b_{t}, g_{t}, b_{t+1}\right)$}

As in the previous section, we construct a period- $t$ function $U($.$) that maps economic$ policies into household welfare. The difference is that now $U$ is a function of $g_{t}$ but also of $b_{t}$ and $b_{t+1}$ (while $\tau_{t}$ is chosen optimally given $g_{t}, b_{t}$ and $b_{t+1}$ ). Accordingly, the government's set of admissible actions is the one specified by constraints (25) and (26).

Let us explain how we construct $U($.$) . First, combine (19) with (21) to obtain$

$$
c_{t}+g_{t}+b_{t}-\beta b_{t+1}=l_{t}
$$

Suppose that a vector $\left(c_{t}, l_{t}, g_{t}, b_{t}, b_{t+1}\right)$ satisfies this equality. If one sets $x_{t}=b_{t}-\beta b_{t+1}$, then both (19) and (21) will be satisfied. Hence, we can substitute (28) for (19) and (21)

\footnotetext{
${ }^{24}$ Observe that, when $b_{t}=b_{t+1}=0, \Gamma\left(b_{t}, b_{t+1}\right)$ assumes the value of the scalar $\Gamma$ defined in the previous section as the maximum attainable level of $g_{t}$ when debt is unavailable.
} 
when characterizing the set of attainable sequences. Now define $U$ according to

$$
U\left(b_{t}, g_{t}, b_{t+1}\right) \equiv \max _{\left(c_{t}, l_{t}\right)} u\left(c_{t}, l_{t}, g_{t}\right)
$$

subject to (22) and (28). We have the following result.

Lemma 2 If $\left\{g_{t}, b_{t+1}\right\}_{t=0}^{\infty}$ is an attainable sequence, then $U\left(b_{t}, g_{t}, b_{t+1}\right)$ gives the highest attainable value for the typical household period utility at each date $t$ along an underlying competitive equilibrium path.

Recall that the government's choice of $g_{t}$ has to satisfy $(26)$. That is, the vector $\left(b_{t}, b_{t+1}\right)$ defines the set to which $g_{t}$ must belong. For this reason, it is convenient to express the efficient value of $g$ as a function of $b_{t}$ and $b_{t+1}$. Hence, let $g^{*}\left(b_{t}, b_{t+1}\right)$ be the value of $g_{t}$ that maximizes $U\left(b_{t}, g_{t}, b_{t+1}\right)$ under the constraint $\gamma \leq g_{t} \leq \Gamma\left(b_{t}, b_{t+1}\right)$. Furthermore, the efficient policy $\left\{g_{t}^{*}, b_{t+1}^{*}\right\}_{t=0}^{\infty}$ must maximize $\sum_{t=0}^{\infty} \beta^{t} U\left(b_{t}, g_{t}, b_{t+1}\right)$ over the set of attainable policies. From Lemma 1 , we know that $b_{t+1}^{*}=0$. It follows that $g_{t}^{*}=g^{*}(0,0)$ for every $t$. Hence, as established in that lemma, the efficient level of $g_{t}$ is time invariant. It should also be clear that $g^{*}(0,0)$ is equal to the scalar $g^{*}$ of the previous section.

We need to introduce some additional structure on $U$, which we will need to prove subsequent results. For notational convenience, let us denote $b_{t}$ and $b_{t+1}$ by, respectively, $b$ and $b^{\prime}$. Denote the partial derivatives of $U$ by $U_{b}, U_{g}$ and $U_{b^{\prime}}$. Analogous notation is used for the second-order derivatives. We assume that $U$ is strictly concave in $g$, so that

$$
U_{g g}\left(b, g, b^{\prime}\right)<0
$$

Furthermore, we postulate that the partial derivatives satisfy some intuitive conditions:

$$
U_{b^{\prime}}\left(b, g, b^{\prime}\right) \geq 0, U_{b g}\left(b, g, b^{\prime}\right)<0, U_{g b^{\prime}}\left(b, g, b^{\prime}\right)>0
$$

and

$$
U_{b g}(b, g, b)+U_{g b^{\prime}}(b, g, b)<0 .
$$

Intuitively, if $b$ and $g$ are held constant, an increase in $b^{\prime}$ reduces the amount of distortionary taxes required to balance the government period budget constraint. This justifies the first inequality. Analogously, if $g$ and $b^{\prime}$ are held constant, an increase in $b$ leads to an increase in the tax burden, lowering the marginal utility of $g$. Similarly, $U_{g}$ is a strictly increasing function of $b^{\prime}$. Moreover, if the public debt is held constant over time at a level $b$, then an 
increase in that level requires, for a fixed $g$, an increase in the tax burden to service the debt, lowering the marginal utility of $g$.

We introduce three last, weak restrictions on our environment. First, we assume that

$$
b<\hat{b} \Rightarrow U\left(b, g^{*}(b, b), b\right)>U\left(\hat{b}, g^{*}(\hat{b}, \hat{b}), \hat{b}\right) .
$$

Condition (33) follows from the fact that, if the government keeps its debt constant at some generic level $b$, the amount of distortionary revenue needed to balance its budget will be a strictly increasing function of $b$.

Second, we require that,

$$
\Gamma\left(b, b^{\prime}\right)>\gamma \Rightarrow g^{*}\left(b, b^{\prime}\right)>\gamma
$$

Condition (34) states that $\gamma$ is sufficiently small so that the constraint $g^{*}\left(b, b^{\prime}\right) \geq \gamma$ would bind only if the set $\left[\gamma, \Gamma\left(b, b^{\prime}\right)\right]$ were a singleton.

Finally, we assume that

$$
g^{*}(0,0)<\Gamma(0,0)
$$

Condition (35) ensures that a profligate government is able to overspend without making the public debt deviate from its optimal path.

In example 2 , below, we compute $U\left(b, g, b^{\prime}\right)$ for the primitive utility function $u$ we used in example 1. In section I of the online appendix, we show in the context of example 2 how to compute the value $\bar{B}$, how to construct functions $f^{b}($.$) and \Gamma($.$) , and that U\left(b, g, b^{\prime}\right)$ satisfies all the assumptions laid down in this and the previous subsection under reasonable parameter restrictions.

Example 2 As in example 1, let $u$ be given by (8). As before, (9) and (10) constitute the solution of the typical household problem. Combine (9) with (20) to conclude that $\tau=\left(g+b-\beta b^{\prime}\right)\left(a_{1}+a_{2}\right) / a_{1}$. Plug this result into (10). This yields

$$
c=\frac{a_{1}}{a_{1}+a_{2}}-\left(g+b-\beta b^{\prime}\right)
$$


Combine the last equality with (8) and (9) to conclude that ${ }^{25}$

$$
U\left(b, g, b^{\prime}\right)=a_{1} \ln \left[a_{1}-\left(a_{1}+a_{2}\right)\left(g+b-\beta b^{\prime}\right)\right]+a_{3} \ln g+\ln \left[\frac{a_{2}^{a_{2}}}{\left(a_{1}+a_{2}\right)^{a_{1}+a_{2}}}\right] .
$$

Observe that the intertemporal discount factor $\beta$ helps to shape $U($.$) . The reason is that$ we assumed that $q$ (the price of the bonds traded in the international financial market) is equal to $\beta$. Had we not introduced that assumption, $U$ would depend on $q$ instead of $\beta$.

\subsection{The political environment and the policy game}

The political environment and the policy game are virtually identical to the one of section 3.2 ; we only substitute $U\left(b, g, b^{\prime}\right)$ for $U(g)$. Therefore, in the present context an economy is an array $\left(\beta, U, \gamma, \Gamma, f^{b}, \bar{B}\right)$, a polity is a vector $(\lambda, n)$, and a society is the combination of an economy and a polity.

The players and the probability that a given party will be elected are as in the previous section. A history of policies is now an array $h^{t}=\left(\left(g_{0}, b_{1}\right),\left(g_{1}, b_{2}\right), \ldots,\left(g_{t}, b_{t+1}\right)\right)$. After observing $h^{t-1}$, the date- $t$ incumbent selects a policy $\left(g_{t}, b_{t+1}\right)$. A symmetric political equilibrium is defined exactly as before. ${ }^{26}$ Finally, if $\left\{g_{t}, b_{t+1}\right\}_{t=0}^{\infty}$ is a symmetric political outcome, then the payoff of the date- $s$ incumbent along the equilibrium path is

$$
\Omega_{s}\left(\left\{g_{t}, b_{t+1}\right\}_{t=s}^{\infty}\right)=U\left(b_{s}, g_{s}, b_{s+1}\right)+\lambda g_{s}+\sum_{t=s+1}^{\infty} \beta^{t-s}\left[U\left(b_{t}, g_{t}, b_{t+1}\right)+\frac{\lambda}{n} g_{t}\right]
$$

\subsection{The spendthrift equilibrium}

We now turn to the characterization of an equilibrium outcome that we will use to support other equilibria by means of trigger strategies. That task is not as simple as in the previous section. For example, even if the date- $t$ incumbent believes that all other parties will implement the dictatorial policy $g^{D}$ regardless of the history $h^{t-1}$, it may want to issue debt to fund a level of $g_{t}$ above $g^{D}$.

\footnotetext{
${ }^{25}$ As in example 1, the expression inside the first $\log$ is positive. To see that, it is enough to combine the fact that $c>0$ with equality $(36)$.

${ }^{26}$ At this point, one may feel compelled to consider a game in which date- $t$ actions can depend only on $b_{t}$ and study its corresponding Markov perfect equilibrium. However, the efficient policy would not be an equilibrium outcome in such a game. If the date- $t$ incumbent believes that all other parties will implement the policy $\left(g_{s}, b_{s+1}\right)=\left(g^{*}(0,0), 0\right)$ whenever $b_{s}=0$, then the action $\left(g_{t}, b_{t+1}\right)=\left(g^{*}(0,0), 0\right)$ will be dominated by the action $\left(g_{t}, b_{t+1}\right)=\left(g^{D}, 0\right)$. Thus, given our interest in the implementability of efficient policies, we need to consider a game that does not have a Markov structure.
} 
To characterize the equilibrium set of our political game, it is convenient to define the following function.

Definition 6 The function $G\left(b, b^{\prime}, \lambda\right)$ specifies, for given $\left(b, b^{\prime}\right)$, the level of $g$ that maximizes the incumbent's period payoff.

Thus, $G\left(b, b^{\prime}, \lambda\right)$ solves

$$
G\left(b, b^{\prime}, \lambda\right) \equiv \arg \max _{g}\left[U\left(b, g, b^{\prime}\right)+\lambda g\right]
$$

subject to ${ }^{27}$

$$
g \leq \Gamma\left(b, b^{\prime}\right)
$$

The first-order condition associated with this problem is

$$
U_{g}\left(b, G\left(b, b^{\prime}, \lambda\right), b^{\prime}\right) \geq-\lambda
$$

This condition holds with equality whenever (39) does not bind.

We show in Lemma 5 in section II of the online appendix that $G($.$) is strictly decreasing$ in $b$, strictly increasing in $b^{\prime}$, and increasing in $\lambda$. The intuition behind these properties is simple. If $g$ and $b^{\prime}$ are held constant, an increase in $b$ requires the government to increase its distortionary revenues. Since the definition of $G$ entails finding an optimal balance between government consumption and distortionary taxation, $G$ decreases as $b$ rises. Similar reasoning implies that $G$ increases in $b^{\prime}$. It is clear from (38) that $G$ is increasing in $\lambda .^{28}$

Suppose that the date- $t$ incumbent believes that all other parties will leave a debt $\bar{B}$ regardless of the debt they inherited. If under this assumption the best strategy for the date- $t$ incumbent is to set $b_{t+1}=\bar{B}$, then we have an equilibrium in which the first incumbent enjoys a relatively high payoff and future governments have no option but to set $g_{t}=\gamma$ and keep $b_{t+1}=\bar{B}$. This policy plan corresponds to

$$
\tilde{\sigma}_{t}\left(h^{t-1}\right)=\left(G\left(b_{t}, \bar{B}, \lambda\right), \bar{B}\right) .
$$

Its corresponding outcome is $\left\{\tilde{g}_{t}, \tilde{b}_{t+1}\right\}_{t=0}^{\infty}$, where $\tilde{g}_{t+1}=\gamma$ and $\tilde{b}_{t+1}=\bar{B}$ for every $t$, while

\footnotetext{
${ }^{27}$ Another constraint is $g \geq \gamma$, but it will never bind. This follows from (34) and the fact that $G\left(b, b^{\prime}, \lambda\right) \geq$ $g^{*}\left(b, b^{\prime}\right)$.

${ }^{28}$ The only hurdle in the process of formalizing that reasoning is that constraint (39) binds for some $\left(b, b^{\prime}, \lambda\right)$. As a result, the partial derivatives $G_{b}, G_{b^{\prime}}$, and $G_{\lambda}$ may be undefined at those points.
} 
$\tilde{g}_{0}=G(0, \bar{B}, \lambda)$. That is, the date-0 incumbent sets a value for $g_{0}$ high enough to drive the economy to a steady state characterized by $\gamma$ and $\bar{B}$. We attach to this equilibrium and its corresponding outcome the epithet spendthrift. ${ }^{29}$

For the spendthrift policy to be an equilibrium outcome, two conditions must be met: $(C 1)$ politicians must be sufficiently profligate (that is, $\lambda$ must be sufficiently large);

$(C 2)$ the rate at which an incumbent is able to substitute $g_{t}$ for $g_{t+1}$ cannot be too small.

The intuition underlying these two conditions is relatively simple. For any $\lambda$, a date- $t$ incumbent may have an incentive to raise $b_{t+1}$ to increase $g_{t}$, with the understanding that this will put downward pressure on $g_{t+1}$. That incentive arises because the date- $t$ office rents are equal to $\lambda g_{t}$, while the next period expected rents correspond to $(\lambda / n) g_{t+1}$. The role of condition $(C 2)$ is to ensure that the date- $t$ incumbent is willing to exploit such a tradeoff. However, as $b_{t+1}$ increases, the value of $U\left(b_{t+1}, g_{t+1}, b_{t+2}\right)$ falls. Therefore, there is another source of future payoff loss. Condition $(C 1)$ ensures that the degree of profligacy is high enough so that such a loss is compensated by the increase in the date- $t$ office rents.

In section II of the online appendix we provide a more precise meaning for $(C 1)$ and $(C 2)$ and formally establish that they ensure that the spendthrift policy is an equilibrium. We also show that the payoff function of example 2 is consistent with those two assumptions. In the main text we henceforth assume that conditions $(C 1)$ and $(C 2)$ are satisfied.

\subsection{The political feasibility of the efficient policy}

We now evaluate the conditions under which a political compromise can sustain the efficient policy. To do so, we use trigger strategies that specify reversion to the spendthrift policy plan $\left\{\tilde{\sigma}_{t}\right\}_{t=0}^{\infty}$.

Define the revert-to-spendthrift plan associated with a policy $\left\{g_{t}, b_{t+1}\right\}_{t=0}^{\infty}$ as a plan such that, if the prevailing history is exactly $\left\{g_{t}, b_{t+1}\right\}_{t=0}^{s-1}$, a player sticks to the policy $\left\{g_{t}, b_{t+1}\right\}_{t=0}^{\infty}$; otherwise, the player implements the policy specified in (41). If $\left\{g_{t}, b_{t+1}\right\}_{t=0}^{\infty}$ satisfies

$$
\begin{aligned}
\Omega_{s}\left(\left\{g_{t}, b_{t+1}\right\}_{t=s}^{\infty}\right) \geq & U\left(b_{s}, G\left(b_{s}, \bar{B}, \lambda\right), \bar{B}\right)+ \\
& \lambda G\left(b_{s}, \bar{B}, \lambda\right)+\sum_{t=s+1}^{\infty} \beta^{t-s}\left[U(\bar{B}, \gamma, \bar{B})+\frac{\lambda}{n} \gamma\right]
\end{aligned}
$$

\footnotetext{
${ }^{29}$ The spendthrift equilibrium shares some characteristics with the financial autarky equilibrium of Aguiar and Amador (2011), where a deviation by the government from its promised payments locks the country forever into financial autarky, and as a result the deviating government chooses to set the tax rate at its maximum possible level.
} 
for every $s$, then $\left\{g_{t}, b_{t+1}\right\}_{t=0}^{\infty}$ is a symmetric policy outcome. This is so because inequality (42) ensures that the corresponding revert-to-spendthrift plan is an equilibrium strategy. Observe that condition (42) is sufficient and necessary for a policy $\left\{g_{t}, b_{t+1}\right\}_{t=0}^{\infty}$ to be an equilibrium outcome. Indeed, if (42) were not satisfied at some date $s$, the incumbent could implement $\left(G\left(b_{s}, \bar{B}, \lambda\right), \bar{B}\right)$ and achieve the payoff specified in the right-hand side. Since (42) is a necessary and sufficient condition that any symmetric policy outcome must satisfy, it provides a complete characterization of the set of all symmetric political outcomes.

At this stage, it is worthwhile comparing the spendthrift equilibrium with the dictatorial equilibrium of the previous section. We use each of them as a starting point to characterize, through trigger strategies, an equilibrium set for its corresponding game. As in the dictatorial equilibrium, in the spendthrift equilibrium the date- $t$ incumbent party maximizes its period payoff under the assumption that all other parties will act likewise. Despite their similarity, the dictatorial and the spendthrift threats have different effects. When the public debt is available, the date- $t$ incumbent can use $b_{t+1}$ to influence the actions and the payoffs of future governments. In particular, that possibility allows the party in power to impose harsher penalties.

With some abuse of notation, let $\Omega(g, b)$ denote the payoff of the incumbent party if all parties implement the static policy $(g, b)$. Hence,

$$
\Omega(g, b)=\frac{1}{1-\beta}\left[U(b, g, b)+\left(1-\beta+\frac{\beta}{n}\right) \lambda g\right]
$$

It follows from $(42)$ that the efficient policy $\left(g^{*}(0,0), 0\right)$ is a symmetric political outcome if and only if $\Omega\left(g^{*}(0,0), 0\right) \geq \Omega_{0}\left(\left\{\tilde{g}_{t}, \tilde{b}_{t+1}\right\}_{t=0}^{\infty}\right)$. This inequality can be rewritten as

$$
\frac{\beta}{1-\beta}\left[\Delta U+\frac{\lambda}{n}\left(g^{*}(0,0)-\gamma\right)\right] \geq \Delta V
$$

where $\Delta U \equiv U\left(0, g^{*}(0,0), 0\right)-U(\bar{B}, \gamma, \bar{B})$ and $\Delta V \equiv V(0, G(0, \bar{B}, \lambda), \bar{B})-V\left(0, g^{*}(0,0), 0\right)$. The right-hand side of (44) represents the short-run gain for an incumbent from selecting the spendthrift policy instead of the efficient one. The left-hand side corresponds to its future payoff gain from the implementation of the efficient policy instead of the spendthrift policy. Since $g^{*}(\bar{B}, \bar{B})=\gamma$, it follows from (33) that $\Delta U>0$. Moreover, $g^{*}(0,0)>\gamma$. Therefore, the left-hand side is strictly positive and strictly decreasing in $n$. The right-hand side is also positive, since $V(0, G(0, \bar{B}, \lambda), \bar{B})>V\left(0, g^{*}(0,0), \bar{B}\right) \geq V\left(0, g^{*}(0,0), 0\right)$. 
Consider then the inequalities

$$
\frac{\beta}{1-\beta} \Delta U \geq \Delta V
$$

and

$$
\frac{\beta}{1-\beta} \Delta U<\Delta V
$$

Like in section 3, the analysis depends on which of the two inequalities holds. However, the comparison between $g^{*}$ and the level of $g$ achieved in the absence of coordination- $-\gamma$ in the current setting and $g^{D}$ in section 3, where $\gamma<g^{*}(0,0)<g^{D}$-has critical implications for the consequences of political competition.

Proposition 3 If a society $\left(\beta, U, \gamma, \Gamma, f^{b}, \bar{B}, \lambda, n\right)$ satisfies (45), then the efficient policy $\left(g^{*}(0,0), 0\right)$ constitutes a symmetric political outcome.

If the payoffs satisfy (45), the efficient policy is an equilibrium outcome for any level of political turnover. There was no such result in section 3. It arises here because the efficient policy yields more office rents than those obtained under the spendthrift equilibrium after date zero.

The analysis is richer when inequality (46) holds. Define $N^{b}(\beta, \lambda)$ as

$$
N^{b}(\beta, \lambda) \equiv \frac{\lambda\left(g^{*}(0,0)-\gamma\right)}{\frac{1-\beta}{\beta} \Delta V-\Delta U}
$$

Observe that under $(46), N^{b}(\beta, \lambda)>0$.

Proposition 4 If a society $\left(\beta, U, \gamma, \Gamma, f^{b}, \bar{B}, \lambda, n\right)$ satisfies ( 46$)$, then the efficient policy $\left(g^{*}(0,0), 0\right)$ constitutes a symmetric political outcome if and only if $n \leq N^{b}(\beta, \lambda)$.

The implications of Proposition 4 are entirely different from those of its counterpart under no public debt, Proposition 2. First, while the latter lays down a sufficient condition, Proposition 4 establishes one that is necessary and sufficient. Second, and more importantly, the function $N^{b}(\beta, \lambda)$ establishes the maximum number of parties that makes it possible to sustain the efficient policy through trigger strategies. Thus, when the government is free to borrow, the implementation of the efficient policy requires an upper bound - instead of a lower bound - on the number of competing parties.

The combination of Propositions 3 and 4 implies that the efficient policy can be an equilibrium outcome when either (45) or (46) holds. If the former prevails, the efficient 
policy is an equilibrium outcome for every value of $n$. If the latter holds, then political turnover cannot be too intense. In particular, we have the following result.

Proposition 5 For every economy $\left(\beta, U, \gamma, \Gamma, f^{b}, \bar{B}\right)$, there exists a number $\lambda_{0}^{b}$ such that, if a polity $(\lambda, n)$ satisfies $\lambda>\lambda_{0}^{b}$, then inequality (46) holds. In that case, the efficient policy $\left(g^{*}(0,0), 0\right)$ constitutes a symmetric political outcome if and only if $n \leq N^{b}(\beta, \lambda)$.

We conclude this section with a synthesis of its results. We study the strategic interactions of competing political parties in a dynamic political game where the party in office has unrestricted access to the public debt, provided that it is repayable. If politicians are sufficiently profligate, there is an equilibrium in which the date-0 incumbent sets current public expenditures very high, pushing the public debt up to the point of immiserizing the economy forever, in the sense of leaving welfare stuck at $U(\bar{B}, \gamma, \bar{B})$ for $t \geq 1$. Adopting that equilibrium as a benchmark, we use trigger strategies to characterize the viability of the efficient policy. When political economy motives really matter, the efficient policy can be implemented if political turnover is limited $\left(n \leq N^{b}(\beta, \lambda)\right)$, but not otherwise, in which case the economy can become trapped in a bad equilibrium. Hence, intense political turnover can hurt social welfare considerably when governments have easy access to the public debt.

\section{$5 \quad$ Political turnover and debt limits}

\subsection{Sustaining the efficient policy}

We have found that a low probability of holding power in the future encourages a political compromise when the government cannot borrow, but discourages it when access to debt is unrestricted. We now generalize the model so that the analyses of sections 3 and 4 become special cases. Specifically, we let the public debt be constrained by a legal ceiling $B_{L}$. If $B_{L}=0$, it collapses to the model without debt of section 3 ; if $B_{L} \geq \bar{B}$, we have the model of section 4. In doing so we generate additional qualitative insights that reveal that the interplay of political turnover, constraints on government borrowing and the viability of efficient policies is richer and more subtle than the analyses of the polar cases may suggest.

We maintain the assumption that the conditions that ensure that the spendthrift policy is an equilibrium outcome are satisfied. One can then readily extend the reasoning used in section 4 to establish that, for any $B_{L} \in[0, \bar{B}]$, the constrained spendthrift policy (i.e., 
the spendthrift policy with $B_{L}$ replacing $\bar{B}$ ) also is an equilibrium outcome. Defining $\Delta U_{L}^{*} \equiv U\left(0, g^{*}(0,0), 0\right)-U\left(B_{L}, G\left(B_{L}, B_{L}, \lambda\right), B_{L}\right)$ and $\Delta V_{L}^{*} \equiv V\left(0, G\left(0, B_{L}, \lambda\right), B_{L}\right)-$ $V\left(0, g^{*}(0,0), 0\right)$, it follows that the efficient policy $\left(g^{*}(0,0), 0\right)$ is an equilibrium outcome whenever the net gain from a political compromise to implement $g^{*}, N G C^{*}$, is positive: ${ }^{30}$

$$
N G C^{*} \equiv \frac{\beta}{1-\beta}\left[\Delta U_{L}^{*}+\frac{\lambda}{n}\left(g^{*}(0,0)-G\left(B_{L}, B_{L}, \lambda\right)\right)\right]-\Delta V_{L}^{*} \geq 0 .
$$

We can then study how political turnover affects the viability of the efficient policy for a given $B_{L}$.

Lemma 3 There is a debt level $\widehat{B} \in(0, \bar{B})$ with the property that $G(\widehat{B}, \widehat{B}, \lambda)=g^{*}(0,0)$. If $B_{L}<\widehat{B}$ (the limit on the debt is relatively tight), stronger political turnover facilitates the political viability of the efficient policy. If $B_{L}>\widehat{B}$ (the limit on the debt is relatively loose), weaker political turnover facilitates the political viability of the efficient policy.

Alternatively, we can study how a society can use $B_{L}$ to improve economic policy for a given polity. The previous analysis implies that a debt ceiling hurts the feasibility of the efficient policy whenever $n<\min \left\{N^{0}(\beta, \lambda), N^{b}(\beta, \lambda)\right\}$. In that case, if the parties were playing according to the constrained spendthrift strategy (so that $b_{t+1}=B_{L}$ ) and the debt ceiling were removed, then the parties would be able to coordinate on the efficient policy. ${ }^{31}$ Hence, the removal of a debt ceiling can induce the political parties to forge a compromise that sustains the efficient policy by casting the shadow of an immiserating economic future. On the other hand, when $n>\max \left\{N^{0}(\beta, \lambda), N^{b}(\beta, \lambda)\right\}$ a society is more likely to be able to sustain the efficient policy if it places a tight legal ceiling on the public debt. In sum, the desirability of a legal debt limit hinges on the number of competing political parties. More generally, we have the following result.

Proposition 6 The level of the debt ceiling $\left(B_{L}\right)$ that maximizes the net gain from a political compromise to implement the efficient policy decreases with the degree of political turnover (n). Moreover, the range of parameters under which the efficient policy is politically feasible increases with $n$ if $B_{L}<\widehat{B}$, decreases with $n$ if $B_{L}>\widehat{B}$, and is unaffected by $n$ if $B_{L}=\widehat{B}$.

\footnotetext{
${ }^{30}$ Observe that $\lim _{B_{L} \rightarrow 0} G\left(B_{L}, B_{L}, \lambda\right)=\lim _{B_{L} \rightarrow 0} G\left(0, B_{L}, \lambda\right)=g^{D}$, so the equilibria supported by the revert-to-dictatorship threat in section 3 have the same nature as the equilibria supported by the threat of the constrained spendthrift outcome in the limit when $B_{L} \rightarrow 0$. Similarly, the equilibria supported by the spendthrift threat in section 4 are analogous to the equilibria supported by the threat of the constrained spendthrift outcome in the limit when $B_{L} \rightarrow \bar{B}$.

${ }^{31}$ In this particular case the efficient policy would depend on $B_{L}$, since that would be the initial (i.e., before reform) value of the public debt.
} 
The intuition for this result is as follows. A tighter $B_{L}$ lowers the short-run gain from not cooperating. It also influences the long-run gain from cooperation, affecting the payoffs of households and lowering the parties' expected future rent gain. ${ }^{32}$ Now, the impact of $B_{L}$ on the short-run gain from cooperation is independent of the degree of political turnover, whereas its effect on the future reduction of rents is more important the less intense political turnover is. Thus, a tight $B_{L}$ is more likely to undermine an otherwise feasible political compromise when turnover is low. Conversely, it is more likely to promote an otherwise unfeasible compromise when political turnover is high.

At a more fundamental level, observe that a political compromise can both improve economic outcomes and preserve office rents. The latter effect can be critical to make the compromise sustainable, and is present when limits on the public debt are lax. Since preserving rents is more important when each party expects to hold office frequently, limits on political turnover can improve economic outcomes when the public debt is relatively unconstrained. Conversely, a tight debt ceiling is advisable when political competition is intense. Put simply, the political feasibility of the efficient policy tends to require either a limit on the number of political parties or a cap on the public debt, but not both. ${ }^{33}$

\subsection{Generalizing the cooperative outcome}

Studying the conditions under which the efficient policy is viable makes the tradeoff between political competition and constraints on the public debt very transparent. But suppose the efficient policy is not politically viable. In that case, the outcome need not be the uncoordinated equilibrium and the implementation of the constrained spendthrift policy. Rather, the political parties may seek instead to coordinate on another policy.

Along that line of reasoning, we now consider the best politically feasible cooperative policy among static policies, and study how political turnover and debt ceilings interact to shape that policy. This allows us to establish how those variables affect economic outcomes more generally, under the assumption that some type of political compromise exists among the parties. Interestingly, we will see that the key insights uncovered in the analysis of the political viability of the efficient policy carry over to this more general setting.

\footnotetext{
${ }^{32}$ Since $\lambda\left(g^{*}-g^{D}\right)<0<\lambda\left(g^{*}-\gamma\right)$, the future rent gain from cooperation falls from $\lambda\left(g^{*}-\gamma\right)$ when $B_{L}=\bar{B}$ to $\lambda\left(g^{*}-g^{D}\right)$ when $B_{L}=0$.

${ }^{33}$ It is important to stress that although we take the number of political parties as given, in reality it is endogenous to the country's legislative and electoral rules. Morelli (2004), for example, shows how different electoral systems lead to different equilibrium numbers of political parties. Likewise, Callander (2005) shows how splitting the vote in heterogeneous districts affects the equilibrium level of political competition and the resulting policies.
} 
First, let us define a broader version of the net gains from a political compromise. In equation (47) it is defined with respect to the efficient policy, $g^{*}$, but it can be defined more generally as a function of $g$ :

$$
N G C(g) \equiv \frac{\beta}{1-\beta}\left[\Delta U_{L}(g)+\frac{\lambda}{n}\left(g-G\left(B_{L}, B_{L}, \lambda\right)\right)\right]-\Delta V_{L}(g),
$$

where $\Delta U_{L}(g)$ and $\Delta V_{L}(g)$ are generalizations of $\Delta U_{L}^{*}$ and $\Delta V_{L}^{*}: \Delta U_{L}(g) \equiv U(0, g, 0)-$ $U\left(B_{L}, G\left(B_{L}, B_{L}, \lambda\right), B_{L}\right)$ and $\Delta V_{L}(g) \equiv V\left(0, G\left(0, B_{L}, \lambda\right), B_{L}\right)-V(0, g, 0)$. Observe that, although we allow $N G C$ to vary with $g$, we keep debt constant at 0 under the cooperative policy. The reason is that higher levels of debt in the cooperative equilibrium would only make it more difficult to sustain a political compromise (that is, NGC decreases with $\left.b_{t}\right)$. It is therefore sufficient to restrict the analysis to cases where $b_{t}=0$ for all $t$ under a political compromise. For notational ease, we do not indicate that the cooperative $g$ depends on the level of the debt, with the understanding that it is nil under a political compromise.

Allowing $g \neq g^{*}$, on the other hand, can relax the requirement for the sustainability of the cooperative policy. Let $g^{N}$ be the maximizer of $N G C$. As a consequence, $g^{N}$ is, among the static policies, the one that is sustainable under the broadest set of parameters. To compute $g^{N}$, differentiate (48) with respect to $g$; after some manipulation we have that

$$
\frac{d N G C(g)}{d g}=\frac{1}{1-\beta}\left[U^{\prime}(g)+\left(1-\beta+\frac{\beta}{n}\right) \lambda\right]
$$

Given the concavity of $U(g)$, it follows that $d^{2} N G C(g) / d g^{2}<0$. Hence, $g^{N}$ satisfies $^{34}$

$$
U^{\prime}\left(g^{N}\right)=-(1-\beta+\beta / n) \lambda
$$

From the properties of $U($.$) , it is easy to verify that g^{*}<g^{N}<g^{D}$ for all $\beta \in(0,1)$ and $n \geq 2$. It is also easy to verify that the results in Proposition 6 regarding the political feasibility of the efficient policy extend in an analogous fashion to the political feasibility of $g^{N}$. The only substantial difference is that, unlike $g^{*}, g^{N}$ is always politically feasible when $B_{L}=0,{ }^{35}$ although $N G C\left(g^{N}\right)<0$ is possible if $B_{L}>0$, in which case there would

\footnotetext{
${ }^{34}$ For simplicity, we consider that $\lambda$ is low enough relative to $\beta$ so that $g^{N}<f^{g}(0,0)$ for all $n \geq 2$. Otherwise we would still be able to carry out an economically similar analysis, but the corner solution for $g^{N}$ would require an analytically cumbersome taxonomy that would not be particularly insightful.

${ }^{35}$ To see that, recall that when $B_{L}=0$, the constrained spendthrift policy implies permanent reversion to $g^{D}$. Since that is a static policy outcome, and by construction $g^{N}$ constitutes the best static outcome
} 
be no static $g$ that satisfies $N G C(g) \geq 0 .{ }^{36}$

We can nevertheless be more general and characterize the feasibility of a range of static policy outcomes, which we define as the best politically feasible cooperative policy, $g^{f}{ }^{37}$ It corresponds to the static policy that maximizes $U(0, g, 0)$ provided that it is politically feasible. As before, we consider a game where the underlying strategies specify that all political parties set $\left(g_{t}, b_{t+1}\right)=\left(g^{f}, 0\right)$ when in power if all previous governments have done the same, but otherwise follow the constrained spendthrift policy. Formally,

$$
g^{f}=\arg \max _{g} U(0, g, 0)
$$

subject to $N G C\left(g^{f}\right) \geq 0$.

Henceforth we focus on the case where $N G C\left(g^{N}\right)>0$, so that $g^{f}$ is well defined. In such a case, there are two possibilities. If $N G C^{*} \geq 0$, then $g^{f}=g^{*}$ and the analysis of subsection 5.1 applies. Otherwise, the constraint $N G C\left(g^{f}\right) \geq 0$ binds and $g^{f}$ satisfies

$$
N G C\left(g^{f}\right)=\frac{\beta}{1-\beta}\left[\Delta U_{L}\left(g^{f}\right)+\frac{\lambda}{n}\left(g^{f}-G\left(B_{L}, B_{L}, \lambda\right)\right)\right]-\Delta V_{L}\left(g^{f}\right)=0 .
$$

In words, if $g^{*}$ is not sustainable but $g^{N}$ is, then there is a similarly simple static policy $g^{f}$ that maximizes national welfare conditional on being politically feasible. The following lemma shows that such $g^{f}$ lies between $g^{*}$ and $g^{N}$.

Lemma 4 Suppose that $N G C^{*}<0<N G C\left(g^{N}\right)$. Then $g^{*}<g^{f}<g^{N}$.

We want to understand how debt limits and political turnover affect $g^{f}$. With some abuse of notation, let us define $g^{f}\left(n, B_{L}\right)$ as the level of $g^{f}$ that satisfies (51) implicitly as a function of $n$ and $B_{L}$. We show first that whether more political turnover requires a higher or lower $g^{f}$ to maintain political viability depends on the level of the debt ceiling.

Proposition 7 Suppose that $N G C^{*}<0<N G C\left(g^{N}\right)$. If there is a sufficiently tight ceiling on the public debt $\left(B_{L}\right)$, then an increase in political turnover ( $n$ ) would allow for the political viability of a lower $g^{f}$. Conversely, if $B_{L}$ is sufficiently loose, then an increase in $n$ would require a higher $g^{f}$ to maintain political viability.

\footnotetext{
from the incumbent's point of view, the sustainability of $g^{N}$ when $B_{L}=0$ is assured.

${ }^{36}$ In section III of the online appendix we characterize in more detail the properties of $g^{N}$, including the conditions under which $g^{N}$ is and is not politically feasible.

${ }^{37}$ In section IV of the online appendix we characterize a broader set of static equilibrium outcomes and investigate how the set depends on $n$ and $B_{L}$.
} 
Proposition 7 shows that when the efficient policy is politically unfeasible, the best static policy feasible under a political compromise depends on the intensity of political turnover and on the debt ceiling in a very precise way. If political competition is very intense, the implementation of a 'better' policy (in the sense of differing less from $g^{*}$ ) is possible if society tightens the constraint on the government's ability to borrow. In contrast, when there is weak political turnover, the feasibility of a better policy requires loosening the limits on the public debt. The next result provides a formal meaning of 'better' policies.

Corollary 1 Suppose that $N G C^{*}<0<N G C\left(g^{N}\right)$. If there is a sufficiently tight ceiling on the public debt $\left(B_{L}\right)$, then an increase in political turnover $(n)$ would allow for a political compromise that yields higher welfare. Conversely, if $B_{L}$ is sufficiently loose, then an increase in $n$ would only be compatible with a political compromise that yields lower welfare.

Observe the close resemblance between this result and that of Proposition 6, about the political viability of the efficient policy. In both results there is a negative relationship between the intensity of political turnover and the permissiveness of debt limits in shaping the policy outcome. The difference is that Proposition 6 describes how the tradeoff affects the viability of the efficient policy, while Corollary 1 shows how it shapes the best politically feasible cooperative policy when the efficient one is not politically viable. In effect, a key message from Corollary 1 is that the tradeoff established in Proposition 6 regarding the political viability of the efficient policy is much more general than it may appear at first. In fact, there is a single driving force behind both results (which is also present in the sustainability of $g^{N}$ ). It follows that there is also a single force driving the level of national welfare that can be achieved through a political compromise.

Corollary 2 An increase in the intensity of political turnover coupled with a tightening of the ceiling on the public debt has, through the political viability of better policies, a positive impact on national welfare.

The driving force behind all cases is that, under a sufficiently tight constraint on the public debt, a political compromise lowers future rents from incumbency, while under a sufficiently loose ceiling on the debt a political compromise raises future rents from incumbency. The relative importance of both the rent loss under a low $B_{L}$ and the rent gain under a high $B_{L}$ decreases with the intensity of political turnover, as that makes it less likely that a given political party will enjoy incumbency rents in the future. Therefore, 
better cooperative outcomes tend to be achievable either under a tight debt restriction when power rotates among numerous political parties (because that weakens the importance of the future rent loss), or under a permissive limit on the debt when only a few parties contest power (because that magnifies the importance of the future rent gain).

It is worth noting that this logic can be extended to some settings that we do not explicitly consider. For example, rather than assuming that coordination among the political parties is costless (and there are no collective action-like problems), as we do throughout the text, suppose instead that the parties would need to incur a fixed organizational cost $F>0$ if they wanted to implement a certain static policy $g^{\prime}$. The feasibility of $g^{\prime}$ in such a case would hinge on whether $N G C\left(g^{\prime}\right) \geq F$. It is not difficult to see that the flavor of our findings would remain entirely unchanged, except that the analysis would need to be carried out with respect to a modified $g^{f}$, say $g_{F}^{f}$, that satisfies (50) subject to $N G C\left(g_{F}^{f}\right) \geq F$. Lemma 4, Proposition 7, Corollary 1 and, therefore, Corollary 2 would apply to that modified setting just as they do when $F=0$.

\section{Empirical implications}

Our model sheds light on the relationship among political turnover, debt limits and economic outcomes. Since the model is stylized, it does not lend itself directly to empirical scrutiny. However, its main message, as revealed by Corollary 2, carries important empirical implications. The existence of legal constraints on government borrowing is often disregarded in studies of the effects of political turnover. Similarly, measures of political turnover are not regularly considered in studies of the effects of fiscal constraints. ${ }^{38}$ A direct implication of Corollary 2 is that such omissions can create systematic biases in empirical research. Moreover, simply controlling for the omitted factor is not enough. Rather, Corollary 2 stresses the importance of the interaction between measures of political turnover and debt restraints.

For example, suppose that we want to understand the role of fiscal and debt constraints on economic performance. ${ }^{39}$ For the sake of argument, assume that the constraints are exogenous - or more plausibly, that suitable instruments for the introduction of the con-

\footnotetext{
${ }^{38}$ As noted in section 2, the empirical study of Grembi et al. (2016) is a notable exception.

${ }^{39}$ In our model the only available fiscal constraint is on the level of the public debt. At a more general level, one may consider all rules that prevent a government from increasing either expenditures or debt as real-world counterparts of our theoretical constraint.
} 
straints are available. One may then consider a panel regression of the form

$$
y_{i t}=\alpha_{i}+\alpha_{t}+\alpha_{f} F C_{i t}+\boldsymbol{\alpha}_{\mathbf{x}} \mathbf{X}_{i t}+\epsilon_{i t},
$$

where $y_{i t}$ is an economic outcome correlated with national welfare, $F C_{i t}$ measures fiscal constraints and $\mathbf{X}_{\mathbf{i t}}$ is a vector of controls, with $i$ and $t$ indexing countries and years, respectively. $\alpha_{i}$ is a fixed effect to control for unobserved country characteristics that are constant (or change slowly) over time, whereas $\alpha_{t}$ is a year fixed effect to control for global changes in the variables of interest. Our analysis indicates that the estimated $\alpha_{f}$ should be positive when the panel contains mostly cases with many political parties (when $n$ is high, a low $B_{L}$ - which is equivalent to a tight fiscal constraint-facilitates a political compromise), but negative when it contains mostly cases where $n$ is small. If the panel is relatively balanced between the two cases, the estimated $\alpha_{f}$ would tend to be statistically indistinguishable from zero. Thus, without explicitly considering the degree of political turnover in the analysis, any estimate of $\alpha_{f}$ could be consistent with our model.

How can this ambiguity be fixed? Our model stresses that an appropriate specification would need to incorporate a measure of political turnover $\left(n_{i t}\right)$ and its interaction with $F C_{i t}:^{40}$

$$
y_{i t}=\alpha_{i}+\alpha_{t}+\alpha_{n} n_{i t}+\alpha_{f} F C_{i t}+\alpha_{n f} n_{i t} F C_{i t}+\boldsymbol{\alpha}_{\mathbf{x}} \mathbf{X}_{i t}+\epsilon_{i t} .
$$

The key prediction of our model, spelled out in Corollary 2, is that $\alpha_{n f}>0$ : the impact of a fiscal constraint on economic performance should be greater the stronger political turnover is. An analogous point applies to empirical analyses of the economic consequences of political turnover.

Identifying the parameters of (52) empirically is a tall order; to attempt such an investigation is beyond the scope of this paper. The difficulties range from the endogeneity of the key independent variables to the measurement of all of them. Nevertheless, we can at least investigate whether the main variables of the analysis correlate in a manner consistent with the model.

To do so, we employ dummies to classify the existence of meaningful fiscal constraints and use several proxies employed in the literature to measure the degree of political competition. For the dependent variable we use (the log of) GDP per capita. Strictly speaking, Corollary 2 requires a measure of national welfare as the dependent variable, but welfare

\footnotetext{
${ }^{40}$ Again, assume that fiscal constraints and the degree of political turnover are exogenous to the context of the analysis, or that appropriate instruments are available.
} 
measures are not readily available for many countries and years. Nevertheless, Jones and Klenow (2016) show that GDP per capita and welfare have a correlation of 0.98 .

To represent $n_{i t}$, the definition that is closest in spirit to our model would be a measure of the number of political parties, like the first two below. Since any such measures are imperfect, we also use two alternative definitions to proxy the probability of holding power for a given political party: ${ }^{41}$

1. Weighted number of political parties. Calculated as the inverse of a Herfindahl index of the number of political parties, with weights $(s)$ given by the vote shares of each party: $\left(\sum_{n} s_{i}^{2}\right)^{-1}$.

2. Fractionalization. Calculated as the probability that two representatives picked at random from the legislature will be of different parties.

3. Winning margin. Calculated as 100 minus the percentage of votes obtained by the strongest party.

4. Seat difference. Calculated as 100 minus the difference between the largest and second largest lower house parties in percentage of all seats.

For each of those measures, a higher value indicates a more contested political system. The first two measures are based on data from the World Bank's Political Institutions Database; the other two are from the Democracy Barometer. We take their logs to facilitate interpretation of the correlations.

To define the presence of meaningful fiscal constraints, we use the dataset compiled by and described in Schaechter et al. (2012), which covers national and supranational fiscal rules for IMF members. They distinguish among four types of rules: debt, budget balance, revenue and expenditure rules. For each of those, they codify 4 or 5 specific characteristics and aggregate them into sub-indices for each of the four types of rules. A global index can then be constructed from the four sub-indices. Simply adding up the four sub-indexes, which range from 0 to a maximum that varies from 0.8 for the revenue sub-index to 1.4 for the budget balance sub-index, the global index ranges from 0 to 4 in the sample. We

\footnotetext{
${ }^{41}$ These variables represent two of the key dimensions of political competition emphasized by Bartolini (1999, 2000): contestability and vulnerability. According to the Democracy Barometer, "vulnerability corresponds to the uncertainty of the electoral outcome, which is indicated by the closeness of election results as well as the degree of concentration of parliamentary or legislative seats," whereas "contestability refers to the stipulations that electoral competitors have to meet in order to be allowed to enter the race, [where] effective competition in elections is measured by the existence and the success of small parties" (http://www.democracybarometer.org/concept_en.html).
} 
define the presence of a 'strong' fiscal constraint $\left(F C_{i t}=1\right)$ if the global index is 1.5 or higher. This yields a sample average of 0.15 for $F C_{i t}$.

As the country fixed effects subsume all time-invariant country characteristics, in the vector of controls we include only the ratio of debt to GDP. Controlling for the debt-GDP ratio helps to avoid selection issues, as countries may adopt a fiscal rule precisely when that ratio has been increasing, or has reached a particularly high level. ${ }^{42}$ The data come from the IMF's World Economic Outlook. Overall, there are available data for both fiscal restrictions and political competition measures for 69 countries when the World Bank measures are used, and for 47 countries when the Democracy Barometer variables are employed, for the period 1991-2012.

Table 1: Fiscal Constraints, Political Competition and Economic Performance

\begin{tabular}{|c|c|c|c|c|c|}
\hline Dep. var.: $\log ($ GDP per capita $)$ & $(1)$ & $(2)$ & $(3)$ & $(4)$ & $(5)$ \\
\hline Fiscal Constraint $_{t-1}$ & $\begin{array}{c}0.031 \\
(0.062)\end{array}$ & $\begin{array}{l}-0.081^{*} \\
(0.041)\end{array}$ & $\begin{array}{c}0.072^{* *} \\
(0.033)\end{array}$ & $\begin{array}{c}-0.677^{* *} \\
(0.257)\end{array}$ & $\begin{array}{c}0.127 \\
(0.192)\end{array}$ \\
\hline $\mathrm{Nb}$ of Parties $_{t-1}$ & & $\begin{array}{c}-0.054^{* *} \\
(0.026)\end{array}$ & & & \\
\hline $\mathrm{FC}_{t-1} \times \mathrm{Nb}$ of Parties $_{t-1}$ & & $\begin{array}{c}0.118^{* * *} \\
(0.040)\end{array}$ & & & \\
\hline Fractionalization $_{t-1}$ & & & $\begin{array}{l}-0.010 \\
(0.025)\end{array}$ & & \\
\hline $\mathrm{FC}_{t-1} \times$ Fractionalization $_{t-1}$ & & & $\begin{array}{c}0.209^{* *} \\
(0.095)\end{array}$ & & \\
\hline Winning $\operatorname{Margin}_{t-1}$ & & & & $\begin{array}{l}-0.118 \\
(0.108)\end{array}$ & \\
\hline $\mathrm{FC}_{t-1} \times$ Winning Margin $_{t-1}$ & & & & $\begin{array}{l}0.170^{* *} \\
(0.064)\end{array}$ & \\
\hline Seat Difference $_{t-1}$ & & & & & $\begin{array}{c}0.056 \\
(0.046)\end{array}$ \\
\hline $\mathrm{FC}_{t-1} \times$ Seat Difference $t_{t-1}$ & & & & & $\begin{array}{l}-0.023 \\
(0.045)\end{array}$ \\
\hline Debt/GDP ${ }_{t-1}$ & $\begin{array}{l}-0.146 \\
(0.141)\end{array}$ & $\begin{array}{l}-0.021 \\
(0.023)\end{array}$ & $\begin{array}{l}-0.011 \\
(0.024)\end{array}$ & $\begin{array}{c}-0.250^{* * *} \\
(0.042)\end{array}$ & $\begin{array}{c}-0.232^{* * * *} \\
(0.048)\end{array}$ \\
\hline Country FE & yes & yes & yes & yes & yes \\
\hline Year FE & yes & yes & yes & yes & yes \\
\hline Number of obs & 1,453 & 1,192 & 1,170 & 842 & 840 \\
\hline R-squared & 0.181 & 0.673 & 0.670 & 0.229 & 0.225 \\
\hline
\end{tabular}

The results are presented in Table 1 . Observe that due to the country fixed effects, the parameters reflect partial correlations stemming only from within-country changes in

\footnotetext{
${ }^{42}$ Moreover, authors such as Reinhart and Rogoff (2010) argue that the level of the debt itself can affect economic performance.
} 
policy and in the degree of political competition. For comparison purposes, in column (1) we omit the political variables. That specification might suggest that a fiscal constraint has no effect on economic performance. In each of the remaining four specifications, we proxy $n_{i t}$ by one of the four measures described above. Except for seat difference (column (5)), the interactions with $n_{i t}$ have a positive and statistically significant coefficient. Those correlations suggest that the benefits from adopting a tight fiscal constraint tend to increase with the degree of political turnover, in line with the predictions of the model. For example, an increase of $10 \%$ in the measure for the number of parties is associated with a $0.6 \%$ increase in GDP per capita if there is a strong fiscal rule in place - and with a decrease of $0.5 \%$ in GDP per capita otherwise. ${ }^{43}$

\section{Concluding remarks}

We study how ceilings on the public debt and the number of competing political parties jointly affect the feasibility of policies in a political system that exhibits turnover. Due to political economy frictions, the efficient policy is implemented only if the political parties forge a compromise between them, a central facet of policymaking in democracies. We find that when the government faces tight limits on its ability to finance its expenditures through debt, a high number of competing political parties helps to induce good policies from society's perspective. The reason is that intense political turnover reduces the probability that each party will hold power in the future. This lowers the value of future political rents, facilitating a compromise that curbs discretionary spending. Yet the reverse is true when the government is relatively free to finance its expenditures with debt. In that case, efficient policies raise future rents, by preventing equilibria where the economy becomes so indebted that future governments have no choice but to set public expenditures at an inefficiently low level. As a result, having too many competing political parties makes it harder to sustain good policies from society's viewpoint.

We obtain those results by departing from the usual emphasis in the political economy literature on how voters can discipline politicians to an environment where political parties can discipline each other. Similarly, the forces shaping the desirability of a debt limit are

\footnotetext{
${ }^{43}$ Instead of using a dummy that captures all types of fiscal rules, we could define a similar dummy considering only debt constraints. In that case, except for fractionalization, the partial correlations remain qualitatively similar both in terms of magnitudes and of statistical significance. In contrast, if we use dummies representing a 'weak' fiscal or debt restriction-e.g., using criteria flexible enough to yield a dummy whose sample average is roughly 0.5 - most of the coefficients become statistically indistinguishable from zero. This makes sense, as weak rules tend to make it especially easy for governments to circumvent the constraints, making them ineffective and hence blurring any statistical correlation with other variables.
} 
not the ones usually emphasized in the literature, where a debt ceiling curbs rent-seeking behavior but prevents the debt from fulfilling its tax smoothing purpose. Instead, here a debt limit affects the availability of future rents and, through that channel, the viability of an intertemporal compromise among political parties. This novel perspective allows us to highlight the difficulty of simultaneously having high political turnover, unrestricted access to the public debt and efficient economic policies.

\section{Appendix: proofs}

Proof of Proposition 1. Take an economy $(\beta, U, \gamma, \Gamma)$ and let $\lambda$ be any positive real number. Define

$$
\hat{\beta}(\lambda) \equiv\left[1+\frac{U\left(g^{*}\right)-U\left(g^{D}\right)}{V\left(g^{D}\right)-V\left(g^{*}\right)}\right]^{-1} .
$$

$\hat{\beta}(\lambda)$ corresponds to the maximum value of $\beta$ that satisfies (17). Since the ratio $\beta /(1-\beta)$ is a strictly increasing function of $\beta$, any value for $\beta$ below $\hat{\beta}(\lambda)$ satisfies (17). Note also that $0<\hat{\beta}(\lambda)<1$. Observe now that

$$
V\left(g^{D}\right)-V\left(g^{*}\right)=U\left(g^{D}\right)-U\left(g^{*}\right)+\lambda\left(g^{D}-g^{*}\right) \geq U(\Gamma)-U\left(g^{*}\right)+\lambda\left(g^{D}-g^{*}\right) .
$$

Therefore, $\lim _{\lambda \rightarrow \infty}\left[V\left(g^{D}\right)-V\left(g^{*}\right)\right]=\infty$. Since $0<U\left(g^{*}\right)-U\left(g^{D}\right) \leq U\left(g^{*}\right)-U(\Gamma)$, $\lim _{\lambda \rightarrow \infty} \hat{\beta}(\lambda)=1$. Thus, there exists a $\lambda_{0}$ (that does not depend on $n$ ) with the property that, if $\lambda \geq \lambda_{0}$, then $\hat{\beta}(\lambda) \geq \beta$ and inequality (17) holds. Since $g^{*}-g^{D}<0$, condition (16) is not satisfied and the policy $g^{*}$ cannot be implemented with the revert-to-dictatorship strategy.

Proof of Proposition 2. The left-hand side of (16) is strictly increasing in $n$, while its right-hand side does not depend on $n$. Furthermore, (16) holds with equality for $n=$ $N^{0}(\beta, \lambda)$. Thus, if $n \geq N^{0}(\beta, \lambda)$, (16) is satisfied. As a consequence, $g^{*}$ is a symmetric political outcome.

Proof of Lemma 1. The efficient allocation is characterized by constraints (19), (22) 
and (23), plus the first-order conditions

$$
\left\{\begin{array}{l}
u_{c}\left(c_{t}, l_{t}, g_{t}\right)-\theta_{t}-\mu_{t} H_{c}\left(c_{t}, l_{t}, g_{t}\right)=0 \\
u_{l}\left(c_{t}, l_{t}, g_{t}\right)+\theta_{t}-\mu_{t} H_{l}\left(c_{t}, l_{t}, g_{t}\right)=0 \\
u_{g}\left(c_{t}, l_{t}, g_{t}\right)-\theta_{t}-\mu_{t} H_{g}\left(c_{t}, l_{t}, g_{t}\right)=0 \\
-\theta_{t}+\Psi=0,
\end{array}\right.
$$

where $H_{c}, H_{l}$ and $H_{g}$ denote partial derivatives and $\theta_{t}, \mu_{t}$ and $\Psi$ are, respectively, Lagrange multipliers for (19), (22) and (23). We can solve the system composed by (22) and (53) for $c_{t}, l_{t}, g_{t}, \mu_{t}$ and $\theta_{t}$ as a function of $\Psi$. Hence, $\left\{c_{t}^{*}, l_{t}^{*}, g_{t}^{*}\right\}_{t=0}^{\infty}$ is a static sequence. It then follows from (19) that $\left\{x_{t}^{*}\right\}_{t=0}^{\infty}$ is a static sequence as well. Finally, use (23) to conclude that $x_{t}^{*}=0$ and (24) to establish that $b_{t+1}^{*}=0$ for every $t$.

Proof of Lemma 2. Let $\left\{c_{t}\right\}_{t=0}^{\infty}$ and $\left\{l_{t}\right\}_{t=0}^{\infty}$ be any pair of sequences that satisfy the constraints of problem (29). Set $\tau_{t}$ according to (5). Since (22) is equivalent to the equality version of (4), all first-order conditions of the household are met. By setting $x_{t}=$ $b_{t}-\beta b_{t+1}$, we satisfy both (19) and (21). An appeal to Walras' Law establishes that (20) is also met. On the other hand, any attainable pair $\left\{c_{t}\right\}_{t=0}^{\infty}$ and $\left\{l_{t}\right\}_{t=0}^{\infty}$ that is consistent with $\left\{g_{t}, b_{t+1}\right\}_{t=0}^{\infty}$ will satisfy the constraints of the problem in question. Therefore, the maximization is carried over the set of all attainable sequences $\left\{c_{t}\right\}_{t=0}^{\infty}$ and $\left\{l_{t}\right\}_{t=0}^{\infty}$ that are consistent with $\left\{g_{t}, b_{t+1}\right\}_{t=0}^{\infty}$. Therefore, $U\left(b_{t}, g_{t}, b_{t+1}\right) \geq u\left(c_{t}, l_{t}, g_{t}\right)$, with the equality holding exactly for a pair $\left\{c_{t}\right\}_{t=0}^{\infty}$ and $\left\{l_{t}\right\}_{t=0}^{\infty}$ that provides the solution of (29).

Proof of Proposition 3. Combine inequalities (45) and $(\lambda / n)\left(g^{*}(0,0)-\gamma\right)>0$ to conclude that $(44)$ holds. Hence, $\left(g^{*}(0,0), 0\right)$ is an equilibrium outcome.

Proof of Proposition 4. We start with the "if" part. Condition (44) holds with equality when $n=N^{b}(\beta, \lambda)$. Since the left-hand side of (44) is strictly decreasing in $n$, it holds whenever $n \leq N^{b}(\beta, \lambda)$. Thus, the efficient policy is a symmetric political outcome. For the "only if" part, assume that $\left(g^{*}(0,0), 0\right)$ is an equilibrium outcome. Therefore, (44) must hold. As a consequence, $n \leq N^{b}(\beta, \lambda)$.

Proof of Proposition 5. Let $\left(\beta, U, \gamma, \Gamma, f^{b}, \bar{B}\right)$ be a generic economy and $\lambda$ a positive real number. Define $\hat{\beta}(\lambda)$ according to

$$
\hat{\beta}(\lambda) \equiv\left[1+\frac{\Delta U}{\Delta V}\right]^{-1} .
$$

Clearly, $0<\hat{\beta}(\lambda)<1$ and (46) holds if $\beta<\hat{\beta}(\lambda)$. Now let $\bar{\Gamma} \equiv \Gamma(-\underline{B}, \bar{B})$ denote the 
maximum attainable value of $\Gamma$. We have that

$$
\begin{aligned}
\Delta V & =U(0, G(0, \bar{B}, \lambda), \bar{B})-U\left(0, g^{*}(0,0), 0\right)+\lambda\left[G(0, \bar{B}, \lambda)-g^{*}(0,0)\right] \\
& \geq U(0, \bar{\Gamma}, \bar{B})-U\left(0, g^{*}(0,0), 0\right)+\lambda\left[G(0, \bar{B}, \lambda)-g^{*}(0,0)\right] \\
& \geq U(0, \bar{\Gamma}, \bar{B})-U\left(0, g^{*}(0,0), 0\right)+\lambda\left[G(0,0, \lambda)-g^{*}(0,0)\right] .
\end{aligned}
$$

The first inequality follows because $U$ is strictly concave in $g$, is maximized at $g=g^{*}(0,0)$, and $g^{*}(0,0)<G(0, \bar{B}, \lambda) \leq \Gamma(0, \bar{B})<\bar{\Gamma}$. The second inequality follows because Lemma 5 in section II of the online appendix implies that $G(0, \bar{B}, \lambda)>G(0,0, \lambda)$. Furthermore, the difference $G(0,0, \lambda)-g^{*}(0,0)$ is positive and increasing in $\lambda$. Hence, $\lim _{\lambda \rightarrow \infty} \Delta V=\infty$. Since $\Delta U$ does not depend on $\lambda, \lim _{\lambda \rightarrow \infty} \hat{\beta}(\lambda)=1$. Thus, there exists a $\lambda_{0}^{b}$ (that does not depend on $n$ ) with the property that, if $\lambda>\lambda_{0}^{b}$, then $\beta<\hat{\beta}(\lambda)$ and inequality (46) holds.

Finally, if inequality (46) holds, the second statement of the proposition follows from Proposition 4.

Proof of Lemma 3. First define $N^{L}\left(\beta, \lambda, B_{L}\right)$ analogously to $N^{0}(\beta, \lambda)$ and $N^{b}(\beta, \lambda)$ :

$$
N^{L}\left(\beta, \lambda, B_{L}\right) \equiv \frac{\lambda\left[g^{*}(0,0)-G\left(B_{L}, B_{L}, \lambda\right)\right]}{\frac{1-\beta}{\beta} \Delta V_{L}^{*}-\Delta U_{L}^{*}} .
$$

Now recall that $G(\bar{B}, \bar{B}, \lambda)=\gamma<g^{*}(0,0)<g^{D}=G(0,0, \lambda)$. Since $G(b, b, \lambda)$ is continuous in $b$, an appeal to the intermediate value theorem establishes that there exists a debt level $\widehat{B} \in(0, \bar{B})$ with the property that $G(\widehat{B}, \widehat{B}, \lambda)=g^{*}(0,0)$. Since $G(b, b, \lambda)$ is strictly decreasing in $b, \widehat{B}$ is unique. It follows that

$$
\operatorname{sgn}\left[B_{L}-\widehat{B}\right]=\operatorname{sgn}\left[g^{*}(0,0)-G\left(B_{L}, B_{L}, \lambda\right)\right]
$$

Suppose then that $B_{L}>\widehat{B}$. It follows from the approach of section 4 that if $\frac{\beta}{1-\beta} \Delta U_{L}^{*} \geq$ $\Delta V_{L}^{*}$, then $\left(g^{*}(0,0), 0\right)$ is a symmetric political outcome for any $n$. If instead $\frac{\beta}{1-\beta} \Delta U_{L}^{*}<$ $\Delta V_{L}^{*}$, then $\left(g^{*}(0,0), 0\right)$ is a symmetric political outcome only if $n \leq N^{L}\left(\beta, \lambda, B_{L}\right)$.

Consider now that $B_{L}<\widehat{B}$. It follows from the approach of section 3 that if $\frac{\beta}{1-\beta} \Delta U_{L}^{*} \leq$ $\Delta V_{L}^{*}$, then $\left(g^{*}(0,0), 0\right)$ cannot be a symmetric political outcome. If instead $\frac{\beta}{1-\beta} \Delta U_{L}^{*}>$ $\Delta V_{L}^{*}$, then $\left(g^{*}(0,0), 0\right)$ is a symmetric political outcome only if $n \geq N^{L}\left(\beta, \lambda, B_{L}\right)$.

Proof of Proposition 6. Observe first that

$$
\frac{\partial^{2} N G C^{*}}{\partial n \partial B_{L}}=\frac{\beta}{1-\beta} \frac{\lambda}{n^{2}}\left[G_{b}\left(B_{L}, B_{L}, \lambda\right)+G_{b^{\prime}}\left(B_{L}, B_{L}, \lambda\right)\right]<0 .
$$


This implies that $N G C^{*}$ is submodular in $n$ and $B_{L}$. It then follows from the properties of submodular functions that the value of $B_{L}$ that maximizes $N G C^{*}$ is decreasing in $n$. Furthermore, notice that

$$
\frac{d N G C^{*}}{d n}=-\frac{\beta}{1-\beta} \frac{\lambda}{n^{2}}\left[g^{*}(0,0)-G\left(B_{L}, B_{L}, \lambda\right)\right]
$$

so $\operatorname{sgn}\left(d N G C^{*} / d n\right)=-\operatorname{sgn}\left[g^{*}(0,0)-G\left(B_{L}, B_{L}, \lambda\right)\right]$. Thus, $N G C^{*}$ increases with $n$ when $g^{*}(0,0)<G\left(B_{L}, B_{L}, \lambda\right)$, which happens when $B_{L}<\widehat{B}$. Analogously, $N G C^{*}$ decreases with $n$ when $g^{*}(0,0)>G\left(B_{L}, B_{L}, \lambda\right)$, which happens when $B_{L}>\widehat{B}$. Finally, $N G C^{*}$ is unaffected by $n$ when $g^{*}(0,0)=G\left(B_{L}, B_{L}, \lambda\right)$, which happens when $B_{L}=\widehat{B}$.

Proof of Lemma 4. Recall that $N G C(g)$ is concave, strictly increasing for $g<g^{N}$, and strictly decreasing for $g>g^{N}$. Moreover, $g^{*}<g^{N}$. Then, when $N G C\left(g^{N}\right)>0$, if $N G C^{*}<0$ we have that $g^{f}>g^{*}$. Analogously, since $g^{*}$ is the unconstrained maximizer of $U(0, g, 0)$, which is strictly concave, $N G C\left(g^{N}\right)>0$ implies that $g^{f}$ corresponds to the smallest $g$ that satisfies (51). It follows that $g^{f}<g^{N}$.

Proof of Proposition 7. Since $N G C^{*}<0<N G C\left(g^{N}\right), g^{f}\left(n, B_{L}\right)$ adjusts so that condition (51) holds for all relevant pairs $\left(n, B_{L}\right)$. We can then use the implicit function theorem to calculate how $n$ affects $g^{f}\left(n, B_{L}\right)$ :

$$
\frac{d g^{f}\left(n, B_{L}\right)}{d n}=\left.\frac{d g^{f}}{d n}\right|_{N G C=0}=-\frac{\partial N G C / \partial n}{\partial N G C / \partial g^{f}}=\frac{\beta \lambda\left[g^{f}-G\left(B_{L}, B_{L}, \lambda\right)\right] / n^{2}}{U^{\prime}\left(g^{f}\right)+(1-\beta+\beta / n) \lambda} .
$$

Using (49), this expression can be rewritten as

$$
\frac{d g^{f}\left(n, B_{L}\right)}{d n}=\frac{\beta \lambda\left[g^{f}-G\left(B_{L}, B_{L}, \lambda\right)\right]}{\left[U^{\prime}\left(g^{f}\right)-U^{\prime}\left(g^{N}\right)\right] n^{2}} .
$$

By Lemma $4, g^{*}<g^{f}<g^{N}$. The strict concavity of $U($.) then implies that the denominator of the expression above is positive. In contrast, the sign of the numerator hinges on the sign of $g^{f}-G\left(B_{L}, B_{L}, \lambda\right)$. Thus, if $g^{f}>G\left(B_{L}, B_{L}, \lambda\right)$, we have that $\frac{d g^{f}\left(n, B_{L}\right)}{d n}>0$. In that case, an increase in $n$ requires a higher $g^{f}$ to keep condition (51) satisfied. Observe that $g^{f}>G\left(B_{L}, B_{L}, \lambda\right)$ when $B_{L}$ is sufficiently high, since $d G\left(B_{L}, B_{L}, \lambda\right) / d B_{L} \leq 0$. Conversely, $\frac{d g^{f}\left(n, B_{L}\right)}{d n}<0$ when $g^{f}<G\left(B_{L}, B_{L}, \lambda\right)$, in which case an increase in $n$ allows (51) to remain satisfied even with a lower $g^{f}$. This happens when $B_{L}$ is sufficiently low.

Proof of Corollary 1. The proof follows directly from Proposition 7. When $B_{L}$ is sufficiently tight, $g^{f}-G\left(B_{L}, B_{L}, \lambda\right)<0$ and $\frac{d g^{f}\left(n, B_{L}\right)}{d n}<0$. Since $U^{\prime}(g)<0$ for $g>g^{*}$ and 
$g^{f}>g^{*}$ by Lemma 4, then $\frac{d U\left(g^{f}\left(n, B_{L}\right)\right)}{d n}>0$. Analogously, when $B_{L}$ is sufficiently high, $g^{f}-G\left(B_{L}, B_{L}, \lambda\right)>0, \frac{d g^{f}\left(n, B_{L}\right)}{d n}>0$ and $\frac{d U\left(g^{f}\left(n, B_{L}\right)\right)}{d n}<0$.

Proof of Corollary 2. The proof follows directly from the previous results. According to Proposition 6, jointly increasing political turnover and tightening the ceiling on the public debt expands the conditions (i.e., the set of parameters) under which the efficient policy is politically viable. A straightforward extension of Proposition 6 also implies that the joint effect expands the conditions under which $g^{N}$, the static policy that maximizes the net gain from a political compromise, is politically viable. Finally, according to Corollary 1 , the joint effect also improves the economic outcome that is achievable under a political compromise when the efficient policy is not viable but another static policy is.

\section{References}

Acemoglu, D., M. Golosov and A. Tsyvinski (2011a). Power Fluctuations and Political Economy. Journal of Economic Theory 146, 1009-1041.

Acemoglu, D., M. Golosov and A. Tsyvinski (2011b). Political Economy of Ramsey Taxation. Journal of Public Economics 95, 467-475.

Acemoglu, D., T. Reed and J. Robinson (2014). Chiefs: Economic Development and Elite Control of Civil Society in Sierra Leone. Journal of Political Economy 122, 319-368.

Aguiar, M. and M. Amador (2011). Growth in the Shadow of Expropriation. Quarterly Journal of Economics 126, 651-697.

Aizenman, J. and A. Powell (1998). The political economy of public savings and the role of capital mobility. Journal of Development Economics 57, 67-95.

Alesina, A. (1988). Credibility and Policy Convergence in a Two-Party System with Rational Voters. American Economic Review 78, 796-805.

Alesina, A. and G. Tabellini (1990). A Positive Theory of Fiscal Deficits and Government Debt. Review of Economic Studies 57, 403-414.

Arvate, P. (2013). Electoral Competition and Local Government Responsiveness in Brazil. World Development 43, 67-83.

Azzimonti, M. (2011). Barriers to Investment in Polarized Societies. American Economic Review 101, 2182-2204.

Azzimonti, M., M. Battaglini and S. Coate (2016). The Costs and Benefits of Balanced Budget Rules: Lessons from a Political Economy Model of Fiscal Policy. Journal of Public Economics 136, 45-61. 
Baron, D. and J. Ferejohn (1989). Bargaining in Legislatures. The American Political Science Review 83, 1181-1206.

Barro, R. (1974). Are Government Bonds Net Wealth? Journal of Political Economy 82, $1095-1117$.

Bartolini, S. (1999). Collusion, competition and democracy: Part I. Journal of Theoretical Politics 11, 435-470.

Bartolini, S. (2000). Collusion, competition and democracy: Part II. Journal of Theoretical Politics 12, 33-65.

Battaglini, M. (2014). A Dynamic Theory of Electoral Competition. Theoretical Economics $9,515-554$.

Besley, T., T. Persson and D. Sturm (2010). Political Competition, Policy and Growth: Theory and Evidence from the US. Review of Economic Studies 77, 1329-1352.

Besley, T. and M. Smart (2007). Fiscal Restraints and Voter Welfare. Journal of Public Economics 91, 755-773.

Bierbrauer, F. and P. Boyer (2013). Political Competition and Mirrleesian Income Taxation: A First Pass. Journal of Public Economics 103, 1-14.

Bisin, A., A. Lizzeri and L. Yariv (2015). Government Policy with Time Inconsistent Voters. American Economic Review 105, 1711-1737.

Bonomo, M. and C. Terra (2010). Electoral Cycles through Lobbying. Economics \& Politics 22, 446-470.

Bowen, R. and C. Mo (2016). The voter's blunt tool. Journal of Theoretical Politics 28, $655-677$.

Caballero, R. and P. Yared (2010). Future Rent-Seeking and Current Public Savings. Journal of International Economics 82, 124-136.

Callander, S. (2005). Electoral Competition in Heterogeneous Districts. Journal of Political Economy 113, 1116-1145.

Callander, S. and P. Hummel (2014). Preemptive Policy Experimentation. Econometrica $82,1509-1528$.

Canova, F. and E. Pappa (2006). The elusive costs and the immaterial gains of fiscal constraints. Journal of Public Economics 90, 1391-1414.

Chari, V. and P. Kehoe (1990). Sustainable Plans. Journal of Political Economy 98, 783-802.

Chari, V. and P. Kehoe (1999). Optimal Fiscal and Monetary Policy. In Taylor, J. and M. Woodford (eds.). Handbook of Macroeconomics, vol. 1C. North-Holland: Amsterdam. 
Checherita-Westphal, C. and P. Rother (2012). The impact of high government debt on economic growth and its channels: An empirical investigation for the euro area. European Economic Review 56, 1392-1405.

Dixit, A., G. Grossman and F. Gul (2000). The Dynamics of Political Compromise. Journal of Political Economy 108, 531-168.

Drazen, A. (2000). Political Economy in Macroeconomics. Princeton University Press: Princeton.

Fiva, J. and G. Natvik (2013). Do Re-Election Probabilities Influence Public Investment? Public Choice 157, 305-331.

Grembi, V., T. Nannicini and U. Troiano (2016). Do Fiscal Rules Matter? American Economic Journal: Applied Economics 8, 1-30.

Halac, M. and P. Yared (2014). Fiscal Rules and Discretion under Persistent Shocks. Econometrica 82, 1557-1614.

Halac, M. and P. Yared (2015). Fiscal Rules and Discretion in a World Economy. Mimeo.

Jones, C. and P. Klenow (2016). Beyond GDP? Welfare across Countries and Time. American Economic Review 106, 2426-2457.

Laibson, D. (1997). Golden Eggs and Hyperbolic Discounting. Quarterly Journal of Economics 112, 443-478.

Milesi-Ferretti, G. (2003). Good, bad or ugly? On the effects of fiscal rules with creative accounting. Journal of Public Economics 88, 377-394.

Morelli, M. (2004). Party Formation and Policy Outcomes under Different Electoral Systems. Review of Economic Studies 71, 829-853.

Perotti, R. and Y. Kontopoulos (2002). Fragmented Fiscal Policy. Journal of Public Economics 86, 191-222.

Persson, T. and L. Svensson (1989). Why a Stubborn Conservative Would Run a Deficit: Policy with Time-Inconsistent Preferences. Quarterly Journal of Economics 104, $325-345$.

Persson, T. and G. Tabellini (2000). Political Economics: Explaining Economic Policy. MIT Press: Cambridge.

Pettersson-Lidbom, P. (2001). An Empirical Investigation of the Strategic Use of Debt. Journal of Political Economy 109, 570-583.

Reinhart, C. and K. Rogoff (2010). Growth in a Time of Debt. American Economic Review PEPP 100, 573-578.

Ricciuti, R. (2004). Political Fragmentation and Fiscal Outcomes. Public Choice 118, $365-388$. 
Schaechter, A., T. Kinda, N. Budina and A. Weber (2012). Fiscal Rules in Response to the Crisis - Toward the Next-Generation Rules. A New Dataset. IMF working paper $12 / 187$.

Song, Z., K. Storesletten and F. Zilibotti (2012). Rotten parents and disciplined children: a politico-economic theory of public expenditure and debt. Econometrica 80, 27852803. 